Revista lus et Praxis, Año 24, No 1, 2018, pp. 437 - 496

ISSN 0717 - 2877

Universidad de Talca - Facultad de Ciencias Jurídicas y Sociales

Autoría y participación en el derecho sancionatorio administrativo. Hacia una topografía del problema Jaime Couso

Trabajo recibido el 19 de agosto de 2016 aprobado el 28 de marzo de 2017

\title{
Autoría y participación en el derecho sancionatorio administrativo. Hacia una topografía del problema*
}

PRINCIPALS AND ACCESORIES IN ADMINISTRATIVE SANCTIONS LAW. TOWARDS A TOPOGRAPHY OF THE PROBLEM

JAIME COUSO**

\section{RESUMEN}

La potestad de la Administración de imponer sanciones no penales está limitada por el principio de legalidad. Conforme a este principio, sólo la ley puede determinar el ámbito de lo sancionable. Ello asegura que las sanciones sean previsibles para los particulares, y que las decisiones de la Administración no sean arbitrarias ni infrinjan el principio de separación de poderes. ¿Se desprende de ahí un límite a la posibilidad de la Administración de sancionar a quienes, sin haber ejecutado directamente la infracción, tuvieron una relevante influencia en su perpetración? La respuesta a esta pregunta es problemática. La dogmática penal sobre autoría y participación puede ofrecer algunos criterios válidos, pero las diferencias entre el Derecho penal y el Derecho sancionatorio administrativo exigen soluciones diferentes. En particular, el rol de la Administración en la implementación de las políticas públicas definidas por el legislador, y las especiales características de la moderna legislación administrativa, abren mayores espacios a la Administración para extender las sanciones a los intervinientes de primer orden, aun si no ejecutaron directamente la infracción.

\footnotetext{
* Este artículo ha sido preparado en el marco del Proyecto Fondecyt Regular No 1140117 "Intervención delictiva y organización en el Derecho penal internacional y comparado", examinando la pertinencia de la aplicación al campo del Derecho sancionatorio administrativo de categorías que han sido estudiadas para la cointervención delictiva, en materia penal. En el trabajo se desarrolla de forma más extensa el planteamiento bastante más exploratorio que, sobre el mismo tema, formulé en el Seminario "Derecho administrativo-sancionatorio y Derecho penal: hacia una ley de infracciones y sanciones administrativas para Chile", celebrado el 29 de octubre de 2014, en la Universidad Diego Portales. Agradezco, en primer lugar, a mi colega de la Facultad de Derecho de la Universidad Diego Portales, Fernando Londoño, por haberme motivado a indagar sobre este tema y haber discutido conmigo varias de las cuestiones que plantea, así como por haberme instruido acerca de algunos de los casos y de la legislación sectorial relevante. También agradezco las importantes sugerencias formuladas y las referencias aportadas por varios otros colegas y doctorandos de la misma facultad a un primer borrador de este trabajo, en particular, Héctor Hernández, Pablo Soto, Matías Guiloff, Juan Enrique Vargas, Cristián Riego, Rodrigo Vergara y Jaime Cerda. Agradezco, por último, las importantes sugerencias hechas por los árbitros anónimos de la revista lus et Praxis.

** Profesor Titular de Derecho Penal, Universidad Diego Portales. República 112, Santiago, jaime. couso@mail.udp.cl.
} 


\section{ABSTRACT}

The administrative agencies' power to impose non-criminal sanctions is limited by the principle of legality. According to this principle, only the legislature can decide the scope of sanctionable violations. This way, foreseeability of sanctions is guaranteed to the citizens, and decisions of the administrative agencies are kept from becoming arbitrary or from breaching the principle of separation of powers. Does this prevent the Administration from sanctioning those who, without having directly committed the violation, have had a significant influence on this outcome? The answer is problematic. Criminal law doctrine on principals and accessories may offer some valuable criteria, but the differences between Criminal Law and Administrative Sanctions Law demand different solutions. Specially, the role of administrative agencies in the implementation of public policies defined by the legislature and the special features of modern administrative legislation open a wider space for the administrative agencies so as to reach with their sanctions the most senior perpetrators, even if they did not directly commit the violation.

PALABRAS CLAVE

Derecho sancionatorio administrativo, Principio de legalidad, Autoría y Participación.

KEY WORDS

Administrative Sanctions Law, Principle of Legality, Principals and Accessories.

\section{Introducción}

La potestad de la Administración de imponer sanciones no penales por la infracción de normas de derecho administrativo está siendo objeto de creciente atención por parte de la jurisprudencia y de la doctrina.

Una de las cuestiones más debatidas, incluso en el seno del Tribunal Constitucional, ha sido la determinación de las garantías y límites a los que debe someterse dicha potestad; sobre todo, la medida en que unas y otros deben seguir el modelo de las garantías y límites reconocidos en el derecho penal. El caso que más atención ha reclamado ha sido el del principio de legalidad y eventualmente, incluso, la exigencia de tipicidad de las conductas susceptibles de ser sancionadas. ${ }^{1}$

Más allá de la discusión acerca de la intensidad con que esta exigencia es aplicable al derecho sancionatorio administrativo ${ }^{2}$, no parece ser objeto de controversia que la ley puede determinar el ámbito de lo sancionable de

\footnotetext{
1 Sobre el debate doctrinario en torno a esta cuestión, infra, apartado 1.

2 También denominado "derecho administrativo sancionatorio", designación que parece poner el acento en el órgano que impone las sanciones, como un instrumento para la realización de fines públicos, sobre todo gubernativos. En el derecho alemán, la expresión Ordungswidrigkeitenrecht se centra, no en el órgano que ejerce la potestad, sino en el presupuesto normativo (las "infracciones administrativas" o "infracciones reglamentarias"). En este trabajo prefiero, apartándome de ambas alternativas, poner el acento en la dimensión sancionatoria de esta rama o sector del ordenamiento jurídico, para destacar el paralelismo -con convergencias y contrastes- entre el "derecho de sanciones administrativas" y el "derecho de penas".
} 
modo que, para el destinatario de la norma, la posibilidad de ser sancionado en caso de que incurra en cierta conducta sea siquiera previsible ${ }^{3}$. Pero si acaso tal exigencia de previsibilidad puede cumplirse sin exigir a la ley -en su caso, complementada por normas infralegales- la determinación más o menos precisa de la conducta sancionada, que es justamente lo que la garantía de la tipicidad exige a la ley en el caso del derecho penal, es algo debatido ${ }^{4}$. ¿Es necesaria esa descripción precisa, en la ley, para que la sanción administrativa sea previsible? O bien, ¿existe otra razón, distinta de la previsibilidad, que haga exigible al legislador determinar con precisión las infracciones susceptibles de sanción administrativa?

La cuestión puede plantearse, no sólo respecto de la infracción en sí, sino también en relación con la forma de intervenir en ella. Supóngase, por ejemplo, que la Administración pretende sancionar a quien, sin realizar directamente la conducta sujeta a sanción, pagó a otra persona para que actuara a su nombre o, más aun, orquestó un plan de negocios que necesariamente pasaba por infringir la norma administrativa, pero cuidándose de no incurrir directamente en la infracción, y convenciendo a terceros -a cambio de dinero- de que ellos asumieran la ejecución de la actividad. ¿Cuenta la Administración con suficiente cobertura legal para sancionarlo, si la sanción está prevista en la ley para quien, al desarrollar la actividad productiva, incurre directamente en la respectiva conducta? $\mathrm{O}$, planteado en términos de política sancionatoria, ipuede la Administración en todos los casos sancionar a los intervinientes de primer orden ${ }^{5}$-los "peces gordos" - sin vulnerar la exigencia de legalidad de las infracciones y sanciones administrativas? ¿O acaso hay lagunas legales en esta materia?

Para responder a esta cuestión es necesario, como se verá, hacerse preguntas como las que el derecho penal se hace cuando enfrenta el problema de quién debe ser considerado autor de un delito, y bajo qué condiciones puede sancionarse a quien no califica como tal. Esto no quiere decir que el derecho sancionatorio administrativo deba responder esas preguntas de la misma forma como lo hace el derecho penal. Pero no puede dejar de preguntarse: ¿quién incurre en una infracción administrativa?, ¿sólo aquel a quien en el derecho penal se

\footnotetext{
3 Exigencia admitida también por la doctrina contraria a la aplicación del principio de tipicidad al derecho sancionatorio administrativo; por todos, LONDOÑO (2014), p. 164, refiriéndose a la posibilidad de captar el contenido normativo de la regulación, así como la Tribunal Constitucional, rol № 747-07, de 31 de agosto de 2007 , considerando $27^{\circ}$, aludiendo a la posibilidad del funcionario sancionado (en el derecho sancionatorio disciplinario) de "razonablemente prever" el carácter obligatorio de ciertos estándares de desempeño cuya infracción ha de ser sancionada.

4 LONDOÑO (2014), pp. 148-149, con amplias referencias a esta discusión.

5 La expresión se toma prestada del derecho penal internacional, que, en términos politico-criminales, asigna especial prioridad a castigar a the most senior perpetrators.
} 
denomina autor, e incluyendo a los autores mediatos y coautores?, ¿o también quienes el propio derecho penal denomina partícipes (cómplices, instigadores)?

El recurso a estos conceptos jurídico-penales no responde a ningún juicio previo sobre el estatuto del derecho sancionatorio administrativo en su relación con el derecho penal, si acaso el de una rama completamente autónoma, cualitativamente diferente de éste, o el estatuto de una subespecie suya, de la cual se diferenciaría sólo cuantitativamente? Plantear la pregunta en términos de autoría y participación responde más bien a la necesidad de decidir la legalidad de la sanción a unos y otros intervinientes prestando atención, en buena medida -si bien no exclusivamente- a la semántica y lógica de las normas; una referencia obligada si la exigencia de legalidad pretende rendir homenaje a lo que la ley prescribe, justamente por medio de normas. Y una virtud de los términos con que el derecho penal enfrenta la pregunta de quién debe ser sancionado por un delito, es que ellos son el resultado de su interés en qué prescriben las normas. Las consideraciones teleológicas podrán tener su lugar, también, a la hora de decidir quién debe ser sancionado; y un lugar muy relevante en el derecho sancionatorio administrativo, como se verá. Pero la exigencia de legalidad, casi por definición, quiere disciplinar las consideraciones teleológicas, constriñendo en alguna medida a la Administración a atender a ellas sólo hasta donde sean compatibles con lo que la ley ha prescrito.

Por último, más allá del caso de los intervinientes de primer orden, y sobre todo si hay razones para concluir que la legalidad administrativa abre la puerta para considerar infractores a sujetos que, bajo la exigencia de tipicidad penal, no cabría sancionar directamente como autores de la conducta, también se plantea la cuestión de si la legislación administrativa permite -y si acaso buscasancionar a quienes no califican como los intervinientes de primer orden, sino que tienen un papel secundario, de meros cómplices (o inductores).

El artículo se propone dar cuenta de la relevancia de tales preguntas, al tiempo de anticipar, de forma tentativa, algunas respuestas. Para ello se tiene en cuenta la forma como el derecho penal responde a ellas, cuando se trata de la perpetración de delitos (y no de infracciones administrativas), pero destacando en qué medida las diferencias entre el derecho sancionatorio administrativo y el derecho penal han justificado respuestas relativamente distintas a tales preguntas cuando ellas son formuladas en aquel contexto, y no en este. Para esa aproximación tentativa, se tiene especialmente en cuenta la tradición jurídica que más directamente ha influido en el desarrollo de la doctrina sobre la autoría y la participación en nuestro país: la del derecho penal alemán y de algún ordenamiento jurídico afín.

La comparación con el derecho penal hace obligado el examen de una cuestión previa, que parece condicionar la respuesta a varias de las preguntas formuladas más arriba: ¿en qué medida, y por qué razón, el principio de legalidad 
en el derecho sancionatorio administrativo debe entenderse de una forma más o menos coincidente o divergente con la forma como se le entiende en el derecho penal? (1). En seguida, de la mano de algunos casos -reales e imaginarios- se hará patente la necesidad de responder a las preguntas planteadas en esta introducción y se examinará qué elementos aporta, para responder a ellas, la doctrina sobre la autoría y la participación desarrollada por la dogmática penal de inspiración alemana (2). A continuación, se revisará someramente la forma en que el derecho sancionatorio administrativo alemán resuelve los problemas de autoría y participación (3), para finalizar con unas breves conclusiones (4).

\section{Problema previo: alcances del principio de legalidad en el derecho sancionatorioadministrativo. ¿Se exige tipicidad de las infracciones administrativas?}

En el derecho penal, por mandato constitucional, no es posible sancionar una conducta sin que la ley la haya previamente descrito. El TC ha desarrollado esta exigencia sosteniendo que la ley debe describir a lo menos el "núcleo esencial" de la conducta. ${ }^{6-7}$

En el derecho sancionatorio administrativo, en cambio, aun cuando la jurisprudencia del TC no ha dejado de insistir en que la exigencia de tipicidad rige respecto de las infracciones administrativas, ${ }^{8}$ de hecho -en aplicación de su tesis conforme a la cual las garantías propias del derecho penal son aplicables en el ámbito del derecho sancionatorio administrativo "con matices" - tiende a prescindir de la exigencia de que la ley describa conductas sancionables, conformándose con que establezca deberes u obligaciones cuyo incumplimiento puede luego ser sancionado por la autoridad administrativa, echando mano de las competencias específicas, o aun genéricas, que la ley le haya conferido para ello. ${ }^{9}$

6 Van Weezel (2011), p. 64, con referencias a los principales fallos del TC en la materia.

7 Pudiendo dejar entregado el complemento de la misma a una norma de rango infralegal. Corte Suprema, rol № 24, de 4 de diciembre de 1985, considerando $3^{\circ}$.

8 Insistencia que, en cambio, ya no se aprecia en una sentencia referida al derecho sancionatorio disciplinario; Tribunal Constitucional, rol № 747-07, de 31 de agosto de 2007, considerando $25^{\circ}$.

9 Con cierto detalle, la evolución de la doctrina del TC en la materia, hasta la consolidación de esa doctrina en su fallo del año 2006 en el caso "Eléctricas", VAN Weezel (2011), pp. 159 y ss., 167 y ss., 179 y ss. Y si bien en algún fallo más reciente parece volver a exigir derechamente descripción, en la ley, del núcleo esencial de la conducta (Tribunal Constitucional, rol № 1064-12-INA de 10 de octubre de 2013 , considerandos $33^{\circ}, 34^{\circ}$ y $38^{\circ}$, sentencia sobre cuyo contenido e interés me llamó la atención mi colega Pablo Soto), en la práctica su ratio decidendi confirma que la "tipicidad" sancionatorioadministrativa se conforma con el establecimiento de deberes generales a nivel legal (su considerando $38^{\circ}$ : "el principio de tipicidad al traspasarse al ámbito sancionatorio de la Administración admite ciertos 
A nivel de la doctrina, como ya se señaló, derechamente se debate si acaso en el derecho sancionatorio administrativo debe tener aplicación el principio de tipicidad o si, más bien, la exigencia de legalidad se conforma con que la posibilidad de ser sancionado sea previsible, ${ }^{10}$ pudiendo bastar para ello, por ejemplo, con que la ley fije una zona o marco acotado de conductas, dentro de la cual la autoridad administrativa podría tener por configurada la infracción e imponer la sanción. ${ }^{11}$ En la práctica, cuando el TC se conforma con que la ley determine los deberes u obligaciones cuyo incumplimiento es sancionable, hace algo parecido a fijar un marco de conductas, sin exigir realmente la descripción de cada una de ellas. Pero, entonces, no parece tener sentido que el TC siga hablando de tipicidad. La cuestión no es meramente un problema de denominación, pues también está en juego la decisión de si la ley que establece sanciones administrativas está sujeta a las exigencias del artículo 19, $N^{\circ} 3^{\circ}$, incisos $8^{\circ}$ y $9^{\circ}$, de la CPR, como ocurre con las leyes que establecen penas, o si sólo está sujeta a las del principio de legalidad de los actos de la Administración. ${ }^{12}$

En mi opinión, hay buenas razones para asumir que respecto del derecho sancionatorio administrativo no rige una exigencia de tipicidad, tal como se la entiende en el derecho penal. La menor severidad, en general, de sus sanciones ${ }^{13}$

grados de atenuación [...] el legislador no puede ir más allá, porque no puede prever la infinidad de incumplimientos en que puede incurrir una determinada empresa [...] La mayoría de estas disposiciones establecen deberes para las empresas, que eventualmente pueden ser transgredidos. La única forma que encontró el legislador de englobar todos estos deberes, es sancionando la infracción de normas y el incumplimiento de instrucciones y órdenes").

10 A favor de una exigencia estricta de tipicidad en este campo, por ej., ALCALDE (2011), pp. 66-68. Así también un sector de la doctrina administrativista; las referencias en LONDOÑo (2014), p. 148, nota 4. En cambio, abogando por una exigencia de legalidad en sentido débil, que se vería satisfecha por la existencia de un "marco legal administrativo-sancionatorio", Londoño (2014), p. 162. Así también, crítico en general de la importación de las garantías penales por parte del derecho sancionatorio administrativo, ZúÑIGA (2015), pp. 402 y ss.

11 Así, recientemente, Londoño (2014), p. 162.

12 Como sostiene, por ejemplo, el ministro Jorge Correa en su prevención a los considerandos $5^{\circ}$ a $7^{\circ}$ del fallo pronunciado por el TC en el caso "Eléctricas". También en la línea de esta última opinión, y fundando la legalidad de las sanciones administrativas en el artículo $19, \mathrm{~N}^{\circ} 3^{\circ}$, de la CPR, ZÚÑIGA (2015), p. 403.

13 La multa penal no es directamente más severa o "aflictiva" que la multa administrativa. Pero, el régimen de sustitución de la primera, en caso de incumplimiento, es más severo que el de la segunda. En efecto, la pena de multa puede sustituirse -si el condenado no acepta someterse a servicios en beneficio de la comunidad- por reclusión de hasta 6 meses de duración (artículo 49 del CP). Las multas administrativas, en cambio, no tienen un régimen general de sustitución; y la posibilidad de sustituirlas por una medida de encierro permanente (reclusión o prisión) quedó en tela de juicio tras la sentencia del Tribunal Constitucional, rol № 1518-09-INA, de 21 de octubre de 2010, que declaró inaplicable el artículo 169 del Código Sanitario, entre otras consideraciones, por sustituir por vía administrativa, 


\section{es una de ellas, como ha reconocido el TC y alguna doctrina. ${ }^{14}$ La (relativa) au- sencia de una dimensión estigmatizante en sus sanciones -que sí se encuentra en las penas- ${ }^{15} \mathrm{O}$, más exactamente, el hecho de que ellas no necesitan de esa dimensión estigmatizante -que sí sería una condición necesaria para las pe-}

como forma de apremio por el impago de la multa, la sanción original por prisión (considerandos $17^{\circ}$ y $18^{\circ}$ ). Si bien la argumentación del TC en esta sentencia es algo obscura, y parece dejar a salvo la constitucionalidad de una medida de apremio de prisión o arresto, no sustitutivo de la multa, siempre que se decretare por un tribunal a solicitud de la autoridad administrativa, el propio legislador, cuando derogó el artículo 169 del Código Sanitario, pareció haber entendido que ese recurso le está vedado (Historia de la Ley № 20.724, pp. 272-273, disponible en http://www.bcn.cl/historiadelaley/nc/historiade-la-ley/4424/, consultada el 5 de enero de 2016), y reemplazó el apremio de prisión por la ejecución forzada del pago de la deuda sumada a la clausura de los establecimientos y la cancelación de la autorización, entre otras medidas (artículo 174 del Código Sanitario). Y si bien ello no ha impedido la subsistencia de medidas de apremio privativas de libertad, sustitutivas o no, susceptibles de ser decretadas por un tribunal, a solicitud de la autoridad administrativa en caso de incumplimiento de sanciones impuestas por la administración, su régimen de todos modos es claramente menos severo que el contemplado por el artículo 49 del CP para el impago de las multas penales. Así, por ejemplo, el artículo 34 del Código Tributario contempla un apremio de arresto por hasta 15 días (aplicable por ejemplo, por la falta del artículo 97, № 11 del mismo código: retardo en enterar impuestos sujetos a retención o recargo, con la respectiva multa), que la Ley de Mercado deValores, hace aplicable también en este sector (artículo 26 del D.L. № 3.538, D.O. 23/12/1980); y la Ley de Policía Local contempla una norma general de apremio sustitutivo por "reclusión nocturna, reclusión diurna o reclusión de fin de semana, a razón de un día o una noche por cada quinto de unidad tributaria mensual, con un máximo de quince jornadas diarias, diurnas o nocturnas" (artículo 23 de la Ley № 18.287, D.O. $7 / 2 / 1984)$. La convertibilidad de las multas administrativas en privación de libertad es considerada una nota distintiva de la pena de multa, frente a la sanción administrativa de multa, también por el ministro Jorge Correa $-\mathrm{y}$ precisamente para argüir que respecto de las infracciones administrativas no rige el principio de tipicidad- en su prevención a los considerandos $5^{\circ}$ a $7^{\circ}$ de la sentencia pronunciada por el TC en el caso "Eléctricas".

14 Así, STC 1413-09, de 16 de noviembre de 2010. En la doctrina, Van WeEzel (2011), p. 186, de acuerdo con tal criterio ("la mayor gravedad de las sanciones que se autoriza a imponer justifica un criterio más estricto en materia de tipificación"). También LonDOÑo (2014), pp. 159-160 asigna importancia al hecho de que las sanciones administrativas no suponen privación de libertad, sin hacer de ello un criterio autónomo, sino mediatamente relevante por el hecho de que, de tal modo, se mantiene cierta conmensurabilidad entre los inputs y outputs representados por el tipo de ventaja esperada de la infracción, de parte el infractor, y el tipo de desventaja que la sanción representa, lo que legitimaría una fundamentación consecuencialista de la sanción-inadmisible en el derecho penal-y una modulación de la potestad sancionatoria de la Administración a las necesidades del sistema, sin los límites impuestos por una interpretación restrictiva de las conductas susceptibles de ser sancionadas.

15 Y ello incluso tratándose de las penas de multa, cuyo carácter estigmatizante proviene, no de la naturaleza de la sanción (en el sentido del tipo de derechos afectados, que son los mismos en la sanción administrativa de multa), sino más bien del hecho que la sanción es etiquetada como pena, por venir asociada a una falta penal e impuesta en un contexto institucional penal (por un juez con competencia penal, en virtud de una condena penal, registrada como tal). El estigma penal parece tener esta cualidad de transmitirse por asociación simbólica, transmisión que puede producirse en sentido inverso: la naturaleza inequívocamente penal de una sanción tiñe de criminal al sujeto que la sufre, aun antes de que sepamos cuál fue su infracción; así, NiNO (1980), p. 206. 
nas- sería otra de esas razones. ${ }^{16}$ En el derecho alemán, por razones similares a las recién mencionadas, ${ }^{17}$ también se dirigen exigencias menores al derecho sancionatorio administrativo en materia de tipicidad. ${ }^{18}$

En el derecho sancionatorio administrativo, entonces, habría que conformarse con la legalidad de las sanciones, sin exigir estrictamente, tipicidad de las mismas, si por tipicidad se entiende la necesidad de descripción de una conducta precisa, conducta de la cual, a lo menos, el núcleo esencial debe estar contenido en la ley.

Pero, ¿qué exigencias impone el principio de legalidad a las sanciones administrativas?

Las exigencias materiales, entendidas de forma muy general, no son muy distintas a las impuestas por el principio de tipicidad a las leyes que establecen penas.

En relación con las penas, esas exigencias son fundamentalmente: i) dar noticia previa a los destinatarios de la norma acerca de las condiciones bajo las cuales podrían hacerse acreedores de una sanción penal; ${ }^{19}$ y, ii) sujetar el

\footnotetext{
16 Londoño (2014), p. 159 y nota 34, destaca esta diferencia entre las penas y las sanciones administrativas. En mi opinión, aun cuando las sanciones administrativas pueden tener efectos estigmatizantes, la diferencia con las penas podría encontrarse en que estas necesitan esa dimensión estigmatizante para expresar reprobación de la conducta delictiva y para así confirmar simbólicamente el modelo de conducta propuesto por la norma, mientras que las sanciones administrativas no la necesitarían, pudiendo bastarles con su relativo efecto de disuasión individual. El régimen de sustitución de las multas penales por prisión estaría al servicio de esa función de señalar de forma reprobadora la conducta delictiva.

17 Así, por ejemplo, el Tribunal Constitucional alemán (BVerfG, 80) distingue la multa penal, de la que no lo es, en base a: 1) el juicio de desvalor y reproche que subyace a la primera, 2) el ingreso de su constancia en el registro de antecedentes penales y 3) su convertibilidad por privación de libertad en caso de impago, sosteniendo, en consecuencia, que las multas convertibles en privación de libertad tienen naturaleza penal, y su imposición debe ser competencia de los jueces y no de la administración (en este caso, la autoridad fiscal o tributaria). Y si bien el $\S 96$ de la OWiG permite imponer, respecto de las sanciones administrativas de multa, el apremio de arresto (hasta por 6 semanas, en general; $y$ hasta por 3 meses, en caso de pluralidad de infracciones), tal apremio no consiste en privación de libertad sustitutiva de la multa, y sólo se impone en razón de la contumacia de quien, teniendo medios para pagar, no lo hace, medio de apremio cuya constitucionalidad ha sido afirmada por el propio Tribunal Constitucional (BVerfG 43, 101).
}

18 En efecto, si bien es generalmente admitido que las exigencias propias del nullum crimen sine lege, establecidas por la Constitución Federal, y desarrolladas por la jurisprudencia del Tribunal Constitucional alemán para el caso de las penas, son aplicables a las leyes que establecen sanciones administrativas, el propio Tribunal ha sostenido que el mandato de determinación (Bestimmtheitsgebot) no debe aplicarse de forma extrema en el campo de las infracciones administrativas, precisamente en atención a sus consecuencias menos aflictivas que las del derecho penal; así, BVerfG NJW 69, 1164, cit. por GÖHLER (1990), § 3 nm 5.

19 En el derecho penal, esta exigencia se fundamenta en razones de prevención general -sólo puede tener eficacia la amenaza de pena si es conocida por el destinatario de la misma con una referencia 
poder sancionatorio del Estado a límites que eviten un ejercicio arbitrario del mismo -en cumplimiento de un postulado básico del liberalismo- encargando a la ley la determinación de esos límites -en cumplimiento de la dimensión democrática del principio de separación de poderes o funciones. ${ }^{20-21}$

En el caso de las sanciones administrativas, en efecto, también es necesario que la posibilidad de ser sancionado sea previsible para el particular, tal como se ha reconocido en Chile, ${ }^{22}$ y en el derecho comparado. ${ }^{23}$

Por lo que atañe a la exigencia de sujetar el poder sancionatorio de la Administración a límites legales, la fundamentación liberal sigue siendo válida: el Estado, cualquiera que sea el órgano de que se trate, no ha de poder injerir en los derechos y libertades individuales de forma arbitraria. ${ }^{24}$

Sin embargo, en lo que se refiere a la dimensión democrática de separación de poderes, que exige justamente un ejercicio respetuoso del marco fijado por la ley, parece producirse una paradoja, que podría estar en la base de las menores exigencias de determinación -o tipicidad- a que están sujetas las sanciones

más o menos específica a la conducta debida o prohibida- y en base al principio de culpabilidad; sólo puede reprocharse al individuo haber incurrido en una conducta que se le había advertido que no debía cometer; Roxin (1994), § 5, nm. 22-25.

20 En el derecho penal, el principio de legalidad se puede fundamentar, efectivamente, por una parte, en un postulado básico del liberalismo político, que garantiza la libertad del ciudadano frente a la intervención del Estado; y, por la otra, en el principio de separación de poderes, que exige, en particular, una legitimación democrática especial para la imposición de sanciones, mediante la definición legal de los presupuestos y una aplicación del Derecho por parte de los jueces; Roxin (1994) § 5, nm 19-21.

21 Cfr., entre nosotros, VAN WeEZEL (2011), pp. 5-19, contraponiendo estas dos formas de fundamentar (y de precisar las exigencias de) el principio de tipicidad, argumentando que sólo la segunda explica realmente la necesidad de una descripción legal de la conducta.

22 Supra, nota 3.

23 En la jurisprudencia constitucional de los Estados Unidos de América, Grayned City of Rockford, 408 U.S. 104. 108 (1972) ("Insistimos en que las leyes ofrezcan a la persona con inteligencia normal una oportunidad razonable de saber qué está prohibido, de tal modo que pueda actuar conforme a ello. Las leyes vagas son una trampa para el inocente al no proporcionarle fair warning"). En Alemania, el $\S 3$ de la OWiG expresamente establece que "[u]na acción puede sancionarse como infracción administrativa sólo cuando la posibilidad de que se sancione fue determinada por la ley antes de que la acción fuese perpetrada", y la doctrina entiende por tal razón que las exigencias del art. 103 II de la Constitución Federal, desarrolladas en detalle por la jurisprudencia del Tribunal Constitucional para las leyes que establecen penas, también son aplicables a las leyes que establecen sanciones administrativas, entre ellas, la exigencia de previsibilidad de la sanción; GÖHLER (1990), § 3 nm 1-5.

24 Para el caso alemán, GöHLER (1990), § 3 nm 5, también extendiendo a las sanciones administrativas la fundamentación que el Tribunal Constitucional Federal ha ofrecido para el mandato de determinación-a propósito de las penas- consistente en la necesidad de asegurar que la decisión sobre el merecimiento de sanción sea adoptada por el legislador, y de manera general y abstracta (y no por la Administración, de forma ad hoc, podría añadirse). 
administrativas (junto con las diferencias en aflictividad y en el carácter estigmatizante de sus sanciones).

La paradoja consiste en que, mientras en el derecho penal el argumento democrático de separación de poderes es una razón más para que el legislador limite el poder sancionatorio (penal) de los jueces, tipificando estrictamente las hipótesis en que estos pueden intervenir en la esfera de derechos de los particulares; en el derecho administrativo del Estado democrático moderno, la consecución de las políticas públicas decididas por el legislador democrático, que ciertamente vinculan a la Administración a la ley, parecen ser una razón para eximir al propio legislador de una exigencia de limitar demasiado a la Administración en sus potestades, incluso las sancionatorias. Pues las especiales necesidades que Ilevan al legislador a entregar a la Administración tales potestades, y la extraordinaria dependencia en que el legislador se encuentra, para alcanzar los objetivos de política pública que busca con ello, de que los organismos administrativos desarrollen tales políticas contando con medios eficaces, a menudo harán necesario que la Administración cuente con un importante espacio de juego para definir -con fidelidad a los propósitos legislativos- en qué hipótesis es necesaria la intervención. ${ }^{25}$

Esa especial cualidad de la relación entre el legislador y el aplicador de la ley, en el campo del derecho administrativo, supone que la sujeción del segundo a los dictados del primero (la legalidad de los actos de la Administración) puede alcanzarse de mejor manera, en varios sectores de la política pública, con una técnica legislativa que no consista en fijar precisamente las hipótesis en que el segundo puede intervenir y las exactas técnicas para hacerlo -vedándole toda intervención fuera de las mismas-, sino más bien fijándole -con igual precisión- los objetivos que ha de buscar y entregándole la potestad de imponer a los particulares reglas que conduzcan a alcanzarlos. ${ }^{26}$

\footnotetext{
25 Esta llamada de atención sobre la especial necesidad de que la ley, incluso en el campo sancionatorio administrativo, haga posible a la Administración alcanzar los objetivos de política pública que le encomienda, es una nota común en varios de los trabajos más recientes que, justamente por ello, rechazan la aplicación de una exigencia estricta de tipicidad en este campo. LonDOÑo (2014), pp. 160, 155, 151, fundamentando su preferencia por la fijación de estándares legales, en lugar de reglas legales, para la potestad sancionatoria de la Administración, en la necesidad del derecho sancionatorio administrativo de "mejorar el entorno", también MONTT (2010), pp. 74-76, destacando que el derecho sancionatorio administrativo "tiene por objeto asegurar que la autoridad pueda mejorar la realidad", pero admitiendo que su legitimidad debe evaluarse por su respeto a los derechos de las personas, y reconociendo que esas dos tareas pueden entrar en tensión.
}

26 Así, RuBin (1989), pp. 372 y ss., 411 y ss., quien entiende que, en el moderno estado administrativo, la legislación consiste en esencia en directivas que encomiendan a los organismos administrativos la implementación de políticas u objetivos públicos, y que para cumplir con tales directivas, en ciertas áreas de la política pública, la Administración será más eficaz, y más fiel por tanto a la directiva legal, si ésta viene formulada sin especificar la forma en que debe actuar la Administración, es decir, la "regla" 
Por cierto, esta característica de la relación entre legislación y Administración, que puede hacer aconsejable, en ciertas leyes sectoriales, recurrir a lo que Rubin denomina una legislación menos transitiva, o derechamente intransiti$v a^{27}$, es decir, una técnica legislativa que prescinda de la fijación de reglas a la Administración, encomendándole en cambio objetivos, y confiriéndole la potestad de fijar las reglas ella misma, puede entrar en tensión con las exigencias de previsibilidad y de garantía, ${ }^{28}$ que, como se acaba de indicar, también son importantes en el derecho sancionatorio administrativo.

Sin embargo, las especiales condiciones de satisfacción de la dimensión democrática de separación de poderes, en relación con el derecho administrativo, permiten, sin negar vigencia a las exigencias de previsibilidad y garantía, una forma de articulación y colaboración entre la ley que fija las directrices y las medidas de implementación administrativas, que consiga al mismo tiempo niveles razonables de compliance, es decir, de cumplimiento e incluso imposición efectiva a los particulares de los objetivos de política pública buscados, y niveles también razonables de previsibilidad y garantía.

Así, dentro del marco de las competencias sancionatorias que el legislador le ha entregado a un determinado organismo administrativo, éste puede ofrecer -y el legislador puede instruirlo para que lo haga ${ }^{29}$ niveles razonables de

que debe aplicar, sino el fin que debe buscar, lo que puede ir acompañado de la instrucción de que ella fije reglas (sacando partido del hecho que se encuentra más cerca de la realidad sectorial y de sus verdaderas condiciones de operación). Llegué a ser consciente del interés de las tesis de RUBIN para la cuestión de la legalidad de las sanciones administrativas gracias a los trabajos de Guiloff (2012), pp. 130-131; y de Sото (2015), p. 704.

27 RUBiN (1989), p. 372.

28 El propio RUBIN (1989), p. 385 -si bien refiriéndose tan sólo a la legislación que aplican los tribunales, que necesariamente debe ser en alto grado transitiva- reconoce que esta técnica legislativa es una necesidad cuando se trata de fijar reglas de conducta a los particulares, lo que a su vez es una condición de legitimidad de la imposición a los mismos de "consecuencias desagradables", como ciertamente lo son las sanciones. Lo interesante, como se verá a continuación, en el texto principal, es que en el caso de la Administración, ello podría lograrse a través de normas de rango infralegal.

29 Algo así parece ocurrir, por ejemplo, en el artículo 58 de la Ley de Mercado de Valores: "La Superintendencia aplicará a los infractores de esta ley, de sus normas complementarias, de los estatutos y reglamentos internos que los rigen y de las resoluciones que dicte conforme a sus facultades, las sanciones y apremios establecidos en su ley orgánica y las administrativas que se establecen en la presente ley". La ley, en efecto, describe algunas conductas y establece deberes, pero luego, al entregar a la Superintendencia potestad sancionatoria respecto de las prohibiciones y deberes fijados en ella, además le instruye para que la misma Superintendencia desarrolle su propia regulación en materia sancionatoria, a través de los mecanismos que enumera en la disposición reproducida, incluso a través de meras resoluciones. Más allá de la obligación de la Administración de desarrollar reglas que hagan previsibles las sanciones, es digno de mención el hecho de que al legislador, en algunas ocasiones, le ha preocupado que esas reglas sean concretamente accesibles para el destinatario de las prohibiciones, como se puede apreciar en la obligación establecida por el artículo $3^{\circ}$, letra 2), inc. 
previsibilidad estableciendo reglas en normas administrativas, pero también, más concretamente, echando mano de mecanismos que, de hecho, contribuyen más directamente que la propia ley al conocimiento de las reglas de conducta por parte de los particulares: instrucciones, dictámenes, interpretaciones, orientaciones, advertencias, inspecciones, amenazas, audiencias, programas educativos, etc. ${ }^{30}$

Con esos niveles razonables de previsibilidad, si la actividad del organismo respectivo se enmarca, además, en una ley que le fija directrices claras y le entrega competencias sancionatorias -en función del cumplimiento de tales directrices- acotadas a un marco o zona de conductas sancionables y de un rango de sanciones determinado -cuya aflictividad además no alcance la medida característica de las penas- entonces las dimensiones garantista y democrática (relativa a la separación de poderes) del principio de legalidad también parecen razonablemente salvaguardadas, ${ }^{31}$ salvaguardas que, además, llegado el caso, podrán ser revisadas por el tribunal que conozca de una acción o recurso que impugne la decisión del organismo administrativo.

Pero, ¿qué pasa si el legislador sí describe las conductas, es decir, si le fija al organismo con competencias sancionadoras reglas y no sólo directivas, o estándares? ¿Deben interpretarse ellas de modo igualmente flexible o extensi$v o$, para seguir favoreciendo el logro de los objetivos de política perseguidos por la Administración en el respectivo sector? Ello justificaría, por ejemplo, el empleo de la analogía, aun en contra del particular, si incurre en una conducta

segundo, de la Ley Orgánica de la Superintendencia del Medioambiente № 20.417, que dispone que "[L]a normativa que emane de la Superintendencia deberá ser sistematizada de tal forma de facilitar el acceso y conocimiento de la misma".

30 Así RuBin (1989), pp. 404-405: "Más bien ocurre que la mayor parte de la información de las personas sobre las reglas legales proviene de los mecanismos [agencias, organismos] de implementación a los cuales la ley está dirigida en primer lugar" (404).

31 En cambio, como se puede apreciar de lo expuesto en el texto principal, la sola fijación por el legislador de un marco de conductas sancionables únicamente sirve para salvaguardar las exigencias del principio democrático. Pero es dudoso que con ella se salvaguarde en suficiente medida la exigencia de previsibilidad, y aun la de garantía, si la Administración no se somete a sí misma -es de esperar, también por exigencia legislativa- a estándares, reglas y prácticas que, por una parte, den noticia más precisa al particular de qué comportamientos pueden hacerle merecedor de una sanción y, por la otra, confieran mayor racionalidad a la decisión de la Administración de cuándo sancionará y cuándo no, dentro de la zona o marco en que, de conformidad con la ley, puede decidir hacerlo. Me parece que a estas dimensiones de la legalidad de las sanciones administrativas no presta suficiente atención el, por lo demás, pionero planteamiento de Londoño (2014), p. 162, acerca del "marco suficiente de legalidad", constituido por la determinación legal de la zona o marco acotado en que la Administración puede moverse al imponer sanciones, si bien, es cierto, el eje de su planteamiento está en las exigencias que deben dirigirse a la ley que establece infracciones administrativas, y no a la Administración que habrá de aplicarlas. 
materialmente tan perjudicial como la expresamente descrita por el legislador, pero formalmente diversa de ella. ¿Está ello justificado por las especiales necesidades en que se encuentra el derecho administrativo?

En mi opinión, aunque la previsibilidad de esa extensión analógica podría salvarse con medidas positivas de la Administración que den noticia previa a los particulares sobre la ampliación del alcance de la sanción, a ello se oponen, sobre todo, las dimensiones garantista y democrática (de separación de poderes) de la legalidad administrativa. Pues el legislador puede haber buscado deliberadamente acotar las competencias de la Administración, no necesariamente en interés de los particulares afectados por los mecanismos de implementación, sino en el propio interés de la política que ha encomendado a la Administración. ${ }^{32}$ En efecto, como sostiene RUBIN, el legislador bien puede haber decidido, atendiendo al específico organismo administrativo de que se trate, con todas sus complejidades institucionales, al tipo de personal con que cuenta, a su posición pública y sus relaciones interinstitucionales, que prefiere no entregarle competencias muy amplias para la implementación de la política, sino más bien fijarle, a través de una legislación en alto grado transitiva, reglas más bien precisas, que definan estrategias claras, ${ }^{33}$ lo que bien podría traducirse en competencias sancionatorias muy acotadas, referidas a supuestos de hecho bien definidos.

32 Ello puede ilustrarse con el siguiente ejemplo, cercano a casi cualquier particular. La Ley del Tránsito (D.F.L. № 1, del 29 de octubre de 2009), en su artículo 75, inciso $4^{\circ}$, prescribe al conductor de un vehículo liviano asegurarse de que los niños menores de cuatro años transportados en asientos traseros usen sillas de seguridad, salvo en el caso de servicios de transporte de pasajeros en taxis. Se trata de una legislación transitiva, con la que el legislador ha definido de forma relativamente precisa la conducta prescrita, de modo que afectaría la previsibilidad de las sanciones de la Administración la decisión que imponga la sanción frente a una conducta afín, pero distinta, por ejemplo, cuando se trata de un niño de cinco años, o si se trata de uno menor de cuatro años, transportado en un taxi. Podrán invocarse atendibles razones de política pública (el niño de cinco años era pequeño y de bajo peso para su edad; o bien, el viaje en taxi era interurbano y el conductor, pese a contar con silla para niños en el vehículo, no dispuso su uso; y, todo ello, en el contexto de un aumento de accidentes por falta de uso de la silla de seguridad), pero con una decisión de ese tipo se afecta la previsibilidad de la sanción, y su legalidad. Más aún, si la Administración confiriese previsibilidad a esa decisión, por ejemplo, a través de un reglamento que extendiese la sanción a hipótesis de ese tipo, de todos modos se afectaría el principio de legalidad, ahora en su dimensión democrática (y acaso, también, en su dimensión garantista). Pues el legislador, al fijar la política de seguridad en el transporte de pasajeros quiso establecer directamente los límites dentro de los cuales rige la exigencia de una silla de seguridad para niños, apartándose de la política seguida por otros países, que exigen el uso de la misma incluso en servicios de transporte de pasajeros en taxis (como ocurre, por ejemplo, en Alemania; § 21, par. (1a), StVO). Y si bien facultó a la Administración para reglamentar ciertos aspectos de la política "las exigencias y el calendario" de aplicación de la medida), claramente no la facultó para ampliar los límites de exigencia de la medida.

33 Rubin (1989), pp. 411-412. 
Las aprehensiones del legislador, en fin, que pueden explicar su preferencia por una legislación en alto grado transitiva, podrían también combinar consideraciones de política, referidas a los recursos y destrezas de un organismo y su personal, con consideraciones garantistas, por ejemplo, cuando espera de la autoridad administrativa especial cuidado a la hora de distinguir hipótesis que merecen sanción de las que no la merecen, tal vez porque el monto de las multas es especialmente alto, o porque la conducta sancionada es especialmente estigmatizante, lo que puede ocurrir con las que coinciden siquiera parcialmente con conductas punibles bajo el derecho penal.

Por último, también es posible que en el específico sector que el legislador está regulando la función determinante no sea la de "mejorar la realidad", siendo innecesaria una legislación intransitiva.

Algunas de estas razones a favor de una mayor transitividad se dan, me parece, en un área del derecho sancionatorio administrativo poco tratada en el contexto del debate acerca de la aplicación de la legalidad o tipicidad, a saber, el de las sanciones disciplinarias. ${ }^{34}$ En efecto, en primer lugar, respecto de la potestad disciplinaria de la Administración no parece darse la necesidad de que ésta cuente con estándares flexibles para mejorar el entorno mediante outputs que recién es posible discernir ex post, estando en juego más bien una mera necesidad de asegurar el buen servicio, ${ }^{35}$ algo alcanzable en principio con facultades sancionatorias acotadas a hipótesis infraccionales previamente definidas. En segundo lugar, el carácter estigmatizante de las sanciones disciplinarias, dependiente no en última instancia del hecho que se imponen sólo a una persona natural, y que justamente en ella -no en una empresa, ni en el grupo de directivos de la misma- concentran su carga simbólica reprobatoria, es mayor que el que puede apreciarse, en general, en las sanciones administrativas gubernativas. ${ }^{36}$

En fin, todas esas razones pueden explicar la preferencia legislativa por una legislación más transitiva en el campo de las sanciones administrativas.

Los casos difíciles, me parece, se darán cuando nada apoye la suposición de que el legislador tenía razones para buscar limitar especialmente las competencias sancionatorias de un determinado organismo administrativo, sino,

\footnotetext{
34 Que, expresamente, la doctrina contraria a la aplicación de estándares de legalidad más o menos estrictos tiende a dejar a salvo de su argumentación, intuyendo, al parecer, que podría allí haber razones especiales, que requieren un análisis distinto; así, LonDOÑo (2014), p. 150, nota 7, aportando además una razón que será útil, como se verá (infra, nota siguiente, y el texto principal correspondiente), para justificar un tratamiento especial de ese tipo de sanciones.

35 El argumento es del propio Londoño (2014), p. 150, nota 7.

36 Sobre la subdivisión de las sanciones administrativas, entre sanciones gubernativas y sanciones disciplinarias, HeRnÁNDEZ (2011), pp. 445-446.
} 
por el contrario, parezca que quiso entregarle medios eficaces de enforcement, incluyendo la sanción de comportamientos que afecten negativamente la política encomendada, de modo que el cumplimiento leal de las directrices legislativas, orientado al fin buscado por el legislador, exigiría el ejercicio de tales competencias en una hipótesis dada, y sin embargo, acaso por razones de deficiente técnica legislativa, de hecho el legislador haya empleado una legislación transitiva, describiendo, como acreedoras de sanción, unas determinadas conductas y no otras.

En tales casos, en mi opinión, las objeciones de legalidad sólo deben ser atendibles si la Administración no hizo previsible la sanción por medio de los instrumentos de implementación con que cuenta. Sí, en cambio, las hizo previsibles, por ejemplo, dictando un reglamento que especificaba las conductas prohibidas, o bien, estableciendo por medio de dictámenes una interpretación que deja claro que tal conducta se sancionará, o, por último, advirtiendo concretamente al particular y conminándolo a abstenerse de continuar con la actividad, entonces, las objeciones de previsibilidad no serían determinantes, ${ }^{37}$

37 En cambio, precisamente esta es la omisión en que la autoridad sanitaria parece haber incurrido en el "caso Essbio"; Corte Suprema, rol № 7397-2012, de 16 de septiembre de 2013. Así, el problema determinante no sería, en mi opinión, que el artículo 73 de Código Sanitario, entrega a la autoridad sanitaria una competencia sancionatoria definida por medio de una regla, bajo el modelo de lo que RUBIN ha llamado una legislación transitiva (así, Sото (2015), pp. 706 y ss. en un, por lo demás, lúcido análisis del fallo en relación con la técnica legislativa empleada al definir la infracción), sino el hecho de que, teniendo señalado por la ley un objetivo de política claro (entre otros, eliminar o controlar elementos del ambiente que puedan afectar al salud o el bienestar de la población, en el art. 67 del Código Sanitario), y habiéndole sido conferida la potestad de reglamentar las actividades que pueden afectar las condiciones de saneamiento de las ciudades (arts. 68 del mismo código), así como una amplia potestad de sancionar las infracciones a esas y otras reglas establecidas para implementar aquel mandato (el art. $9^{\circ}$, letra a), confiere a la autoridad sanitaria la competencia para "velar por el cumplimiento de las disposiciones de este Código y de los reglamentos, resoluciones e instrucciones que lo complementen, y sancionar a los infractores", competencia desarrollada por el art. 174), no haya ejercido estas facultades, según parece (la verificación de esta cuestión de hecho supera los objetivos y posibilidades de este trabajo), de modo de hacer previsible para el particular que el vertido de aguas contaminadas con fecas en un canal de captación de aguas lluvia podía ser sancionado, pese a tratarse de una conducta distinta de la expresamente sancionada por el Código Sanitario en el artículo 73. Si, en cambio, la autoridad administrativa hubiese hecho previsible esta posibilidad al particular, mediante algún tipo de instrucción, o a los particulares, en general, mediante alguna resolución o reglamento, entonces la sanción cumpliría con las exigencias mínimas de legalidad administrativa, con una cobertura legal distinta de la del artículo 73 del Código Sanitario, cuya cita, aunque induce a error, podría entenderse como un recurso argumentativo, por vía ejemplar, acerca de los alcances de la potestad sancionatoria con que el legislador quiso investir a la autoridad administrativa para velar por objetivos de política tan importantes como los que le encomendó. En esta hipótesis, el fallo de la Corte Suprema, que por lo demás parece preocuparse especialmente de aquella dimensión de la legalidad que está al servicio del cumplimiento de los fines encomendados por el legislador a la Administración, materialmente sería acertado, más allá de sus defectos argumentativos. 
y la decisión sobre la legalidad de la sanción debería atender únicamente a la pregunta, distinta, sobre si el marco fijado por el legislador, entendido teleológicamente, fue sobrepasado o no, pregunta que en el escenario propuesto debe ser respondida de modo negativo.

Ello no equivale a admitir la analogía en contra del sancionado, en la medida que la disposición a aplicar no se transfiere sin más desde el caso regulado al que no lo está. La disposición, más bien, cuya cobertura legal está constituida por las competencias sancionatorias generales entregadas al organismo administrativo, se desprende de la integración entre esa cobertura legal y las actividades de implementación con que el mismo organismo ha especificado las expectativas de conducta, y sólo en la medida que lo haya hecho. Así, la prohibición de analogía en contra del sancionado sigue teniendo sentido, como prohibición de aplicación de una disposición establecida para un caso a otro caso no cubierto por ella, lo que afectaría la previsibilidad de la sanción y los límites garantistas al poder sancionatorio de la Administración.

Tampoco cabría, en el escenario propuesto, hablar propiamente de una "interpretación diferenciada" (gespaltene Auslegung) de una misma norma, entre el derecho penal y el derecho de sanciones administrativas, cuando una misma infracción tiene sanciones de ambas ramas del derecho, pues la conducta que no califica como delito, por no realizar el tipo, tampoco satisface las exigencias de la misma descripción típica para efectos del derecho administrativo, pero puede llegar a constituir una infracción administrativa sancionable en virtud de un conjunto (integrado) de otras disposiciones, de rango legal y administrativo. ${ }^{38}$

En resumen, el principio de legalidad de las infracciones y sanciones administrativas no exige la descripción precisa, en la ley, de las conductas

\footnotetext{
38 En Alemania la cuestión de la interpretación extensiva, en el campo del derecho sancionatorio administrativo, ha sido abordada a propósito de dos tópicos. Por una parte, el de la prohibición de analogía en contra del sancionado, que se entiende aplicable no sólo al derecho penal, sino también al derecho de las sanciones administrativas, como el Tribunal Constitucional Federal lo ha reconocido; GÖHLER (1990), § 3 nm 9; también SCHWACKE (2006), p. 6, reconociendo que, en esta rama, la distinción entre interpretación de la ley (que ciertamente puede hacerse "en contra del afectado") y analogía (que no puede aplicarse en contra el afectado) puede ser muy difícil en los casos límite. Por otra parte, la cuestión se plantea desde el tópico de la gespaltene Auslegung, criterio según el cual el método de interpretación y aplicación de la ley dependería de la cuestión de las consecuencias jurídicas que penden en el caso concreto, de modo que un comportamiento determinado puede, por ejemplo, estar prohibido desde el punto de vista civil, y dar lugar a indemnización de perjuicios, pero desde el punto de vista penal puede ser conforme a derecho, posibilidad que es admitida, si bien por un sector minoritario de la doctrina, justamente para esas dos ramas del ordenamiento jurídico, pero precisamente no para la relación entre derecho sancionatorio administrativo y derecho penal;; por todos, BuCK-HeEB (2010), pp. 26 y ss.
} 
cuya perpetración es sancionable por la Administración. Sí exige, en cambio, por una parte, que el ejercicio de la actividad sancionatoria de la Administración tenga su fundamento en potestades sancionatorias, siquiera generales, establecidas por el legislador para que la Administración -y/o los tribunales- pueda reaccionar frente comportamientos que, de diversa forma, infringen normas administrativas. También exige, por otra parte, que el legislador o la Administración hayan hecho previsible, para el particular, tanto las hipótesis que lo exponen a ser sancionado, como las sanciones mismas que pueden serle impuestas. Además, si al entregar esas potestades sancionatorias, el legislador busca la consecución de determinados objetivos de política pública, la legalidad supone -en el caso de un marco legal intransitivo- que aquellas sean ejercidas en aras de la consecución de estos. Ese estándar, en la medida que se conforma con que la ley establezca un marco general, es poco menos exigente con el legislador que el formulado por la jurisprudencia del TC (que le exige fijar los deberes cuya infracción es sancionable), pero, en la medida que demanda de la Administración hacer previsibles las sanciones mediante reglas más claras, es más exigente con ella en comparación con la doctrina del TC (que apenas le exige verificar que el comportamiento infringe de cualquier modo la norma). Con todo, las exigencias impuestas por la ley son mayores si, a través de una legislación transitiva, el legislador ha definido de forma taxativa las hipótesis específicas en las que el particular puede ser sancionado, pues entonces la Administración no puede extender sus potestades sancionatorias más allá de ellas, a menos que, excepcionalmente -en los casos difíciles- el cumplimiento más fiel de las directivas legales, en aras de la consecución de los objetivos de política pública para cuya consecución les fueron conferidas tales potestades, exija justamente sancionar conductas que no están incluidas expresamente en el catálogo legal, pero cuyo castigo, además de razonablemente vinculado con la ratio legis, es claramente previsible para el particular a partir de las reglas establecidas y comunicadas por la propia Administración.

\section{Autoría y participación en el Derecho penal y en el Derecho sancionatorio administrativo}

Estrechamente vinculadas con la cuestión de la legalidad de las infracciones administrativas se encuentran las preguntas expuestas al comienzo de este trabajo. ¿Tiene cobertura legal suficiente la Administración para sancionar en todos los casos a los intervinientes de primer orden en una infracción? ¿O se encuentra con lagunas legales que se lo impiden?Y, más allá de los intervinientes de primer orden, ¿la legislación administrativa permite -y acaso busca- que se sancione a los intervinientes secundarios? 


\subsection{Casos y problemas}

Para abordar estas cuestiones comenzaré exponiendo resumidamente dos casos reales, decididos recientemente por la autoridad administrativa y los tribunales chilenos, que son analizados focalizando la atención exclusivamente en las cuestiones relevantes en materia de autoría y participación, dejando de lado problemas jurídicos que pueden ser decisivos para resolver el caso, como la cuestión de si acaso la infracción imputada realmente se produjo y si tiene el alcance que la autoridad administrativa supone, pero que se encuentran claramente fuera del foco de interés de este trabajo. Junto a ellos, se proponen otros casos y situaciones para dar cuenta de algunos problemas adicionales de la legalidad de la sanción a los diversos intervinientes en una infracción administrativa.

\section{a. El caso Cascadas $^{39}$}

En este caso, la Superintendencia de Valores y Seguros (SVS) imputó a Julio Ponce Lerou, controlador de las "sociedades cascadas" ( $y$, a través de éstas, de la compañía minera no metálica SQM), la realización de operaciones en bolsa en infracción del Título XVI de la Ley de Sociedades Anónimas (LSA), es decir, operaciones con empresas relacionadas, contrarias al interés social. En esencia, las operaciones consistieron en que ciertas "sociedades cascadas" (las "vinculadas" y/o "instrumentales") vendieron acciones a un precio bajo, y meses después las volvieron a adquirir a un precio más alto, lo que perjudicó a los accionistas minoritarios, pero no a los controladores -fundamentalmente, Ponce Lerou- en la medida que las operaciones se efectuaron con otras "sociedades cascadas", controladas por ellos mismos, que por esa vía obtuvieron financiamiento y oportunidades de negocio lucrativas. ${ }^{40}$

\footnotetext{
39 Los hechos están tomados de la Resolución Exenta № 223, de 2 de septiembre de 2014, de la Superintendencia de Valores y Seguros, que aplicó sanciones de multa, entre otros, a Julio Ponce Lerou, y a la Corredora de Bolsa Larraín Vial S.A., por infracciones a la Ley de Sociedades Anónimas y/o a la Ley de Mercado de Valores. Con posterioridad, el $29^{\circ}$ Juzgado Civil de Santiago, en sentencia dictada en la causa rol 21.500-2014, de 2 de diciembre de 2015, acogió sendos recursos de reclamación interpuestos por la corredora Larraín Vial y por el socio de la misma, Leonidas Vial, en contra de la referida resolución de la SVS, pero sin examinar ni pronunciarse sobre las cuestiones que interesan en este trabajo, sino, fundamentalmente, por no haber actuado los sancionados con intención ni conocimiento del plan o esquema que haría de las operaciones encomendada por las sociedades caso Cascadas unas "transacciones ficticias con valores", fuera de que la formulación de cargos se habría efectuado una vez transcurrido el plazo de prescripción.

40 La Resolución Exenta № 223, de 2 de septiembre de 2014, de la Superintendencia de Valores y Seguros, pp. 5-9.
} 
La misma SVS imputó a Larraín Vial S.A. Corredores de Bolsa la infracción del art. 53 , inc. $2^{\circ}$, de la Ley de Mercado de Valores (LMV), que prohíbe efectuar, o aun inducir o intentar inducir, que se efectúen transacciones ficticias con valores.

Las defensas de Ponce Lerou y de Larraín Vial esgrimieron argumentos que dan cuenta de varios de los problemas de autoría y participación planteados más arriba.

En efecto, la defensa de Ponce Lerou objetó que las infracciones al Título XVI de la LSA se refieren a "la sociedad", no a sus directores, de modo que Ponce Lerou no pudo incurrir en ellascomo persona natural. Y la responsabilidad de los directores por las infracciones en que incurrieren las personas jurídicas, establecida en el art. 133 de la misma Ley-considerada por la defensa una excepción calificada al principio de la personalidad de la responsabilidad infraccional- exige de parte del director participación en el hecho constitutivo de la infracción. Y el caso sería que Ponce Lerou no participó en tales hechos, pues las operaciones de bolsa -efectuadas por el corredor- no requieren la intervención directa de la sociedad, ni hay certeza de quiénes serán los adjudicatarios, de modo que no se sabe -no lo sabía Ponce Lerou- si serán o no empresas relacionadas.

Por su parte, la defensa de Larraín Vial objetó que no se le podía imputar a la corredora infringir la prohibición de realizar transacciones ficticias, pues quienes "transan" valores son el vendedor y el comprador de las acciones, y no el intermediario de la compraventa, añadiendo que esta restricción tiene sentido pues el corredor no conoce el trasfondo de la operación (si es ficticia o no).

Como se puede apreciar, la objeción de Ponce Lerou consiste explícitamente en que la infracción "principal" (operaciones con empresas relacionadas) la perpetró la sociedad, no él, pues le falta la cualidad especial requerida por la disposición para el autor de la infracción (ser una "sociedad"), lo que implícitamente supone, además, descartar una posible responsabilidad por parte suya a título de "inductor" de la sociedad, forma de intervención que sería "impune" (de hecho, no se contempla en la LSA). Por su parte, por lo que atañe a la infracción que podría denominarse "vicaria" (la del art. 133 de la LSA), la objeción explícita de la defensa consiste en que Ponce Lerou no incurrió en ella, pues no participó directamente en los hechos (no efectuó la operación); la implícita consiste en que una intervención indirecta o mediata -a través de su influjo sobre la corredora de bolsa- no basta. Son, pues, defensas que aluden a los problemas de autoría y participación.

La objeción de Larraín Vial, por su parte, consiste explícitamente (de nuevo) en que la infracción de la prohibición de efectuar transacciones ficticias sólo la pueden perpetrar quienes intervienen como vendedor o comprador, no así un intermediario, por más que éste haya ejecutado materialmente los actos que dan lugar a la misma; implícitamente, la objeción también supone descartar 
una responsabilidad por la mera cooperación en la conducta del verdadero responsable (comprador y vendedor), es decir, la "impunidad" del cómplice. También se trata de defensas, como se ve, que aluden a problemas de autoría y participación.

\section{b. El caso Blackout ${ }^{41}$}

En este caso, la Superintendencia de Electricidad y Combustibles (SEC) cursó una multa ascendente a 1.200 unidades tributarias anuales -unos 700.000 dólares de la época ${ }^{42}$ - en contra de la compañía eléctrica Endesa S.A. por la interrupción del suministro de energía eléctrica que afectó al Sistema Interconectado Central, el día 24 de septiembre de 2011, en infracción de la obligación de las empresas concesionarias de "mantener las instalaciones en buen estado y en condiciones de evitar peligro para las personas o cosas", impuesta por el art. 139 del D.F.L. № 4 de 2006, ${ }^{43}$ en relación con el art. 14, c), del D.S. № 291 de 2007, que obliga a las empresas concesionarias a "mantener conectadas sus instalaciones [...] sin afectar la calidad del servicio".

La defensa de Endesa consistió, en lo que aquí interesa, en que el blackout se produjo por un "caso fortuito", consistente en una falla personal de un funcionario, y no por una conducta imputable a la empresa. Esa defensa supone una apelación implícita al topos de la "personalidad" de la infracción administrativa -la falla fue del funcionario, no de la empresa- unida al rechazo de una responsabilidad "vicarial" de la empresa por las fallas de sus empleados. Esto parece no haber convencido a la Corte Suprema, tribunal que confirmó la responsabilidad de Endesa argumentando que el art. 139 del D.F.L. $N^{\circ} 4$ de 2006 fundamenta una responsabilidad vicaria (sin llamarla de este modo) de la concesionaria, que "debe hacer todo lo necesario, desde el punto de vista de los dispositivos y de las personas que los operan, para que ellos funcionen adecuadamente [...] ya que esa es una manera en que el deber de mantención que le compete se concreta" ${ }^{44}$ haciendo una interpretación claramente forzada del concepto de "instalaciones", para dar cobertura legal a la sanción.

\footnotetext{
${ }^{41}$ Los hechos se toman de la sentencia de la Corte Suprema, rol № 9551-2014, de 4 de septiembre de 2014.

42 Multa que fue posteriormente reducida a 400 UTA por sentencia de la Corte de Apelaciones de Santiago.

43 Decreto con Fuerza de Ley № 4, de 12 de mayo de 2006, del Ministerio de Economía Fomento y Reconstrucción (D.O. 5/2/2007), que fija el texto refundido, coordinado y sistematizado del Decreto con Fuerza de Ley № 1, de Minería, de 1982, Ley General de Servicios Eléctricos, en materia de Energía Eléctrica.

44 Corte Suprema, rol № 9551-2914, de 4 de septiembre de 2014, considerando $13^{\circ}$.
} 
Como se ve, también en este caso, la defensa puede ser reconducida a un problema de autoría y participación, argumentando la falta de responsabilidad de la organización en cuyo seno uno de sus empleados incurre en una conducta negligente: por el ejecutor individual de la infracción no responde la persona jurídica que le asignó la función en la que aquél tuvo un desempeño defectuoso.

\section{c. Círculo de intervinientes sancionables: consideraciones de política sancionatoria y de legalidad administrativa}

Desde el punto de vista de los intereses de la política sancionatoria de la Administración, la situación de Ponce Lerou, en el Caso Cascadas, y la de Endesa, en el Caso Blackout, aluden al problema de si la ley ofrece cobertura legal para hacer efectiva la responsabilidad de los intervinientes de primer orden que, sin embargo, no realizaron directamente, en una primera aproximación formal, la conducta a que se refiere la disposición infringida.

El problema también se puede presentar en otros casos imaginables, a los que se hará referencia más adelante, como el de las emisiones que exceden la norma ambiental, provenientes de faenas mineras explotadas en beneficio de una empresa que no interviene directamente en la explotación -no es titular de la fuente de emisión- sino la externaliza a través de filiales o de pequeños proveedores no relacionados; o el caso del transportista que, sin incurrir directamente en la conducta, instruye al conductor para que éste reciba una carga peligrosa sin requerir instrucciones escritas del expedidor; o, en fin, el caso de quien instruye a una persona que se encuentra en condiciones psíquicas deficientes para que lo conduzca en automóvil a determinado lugar.

Respecto de este primer grupo de casos, el objetivo de política del legislador claramente apunta a hacer sancionables estos comportamientos. De modo que el uso de una técnica legislativa "transitiva" en las respectivas legislaciones sectoriales puede verse, en principio, como una deficiencia no buscada, de modo que, si se garantiza la previsibilidad de la sanción, parece justificado un programa de implementación que vaya más allá de la letra de la ley, permitiendo sancionar a los intervinientes de primer orden.

La situación de Larraín Vial en el Caso Cascadas, en cambio, parece aludir más bien a la cuestión de si existe cobertura legal para -y de un interés de la Administración en-sancionar a intervinientes con un rol más bien secundario, de cooperación con los intervinientes de primer orden.

La misma cuestión se plantea en el caso del conductor que recibe una carga peligrosa sin pedir las instrucciones escritas del expedidor, por orden -O mediando tolerancia- del transportista; o el caso de quien, a solicitud de ella, presta a una persona en condiciones psíquicas deficientes su automóvil. 
Respecto de este segundo grupo de casos, no es claro que el objetivo de política del legislador apunte a hacerlos sancionables. Pero puede ser resorte de la Administración ampliar la persecución, salvada la previsibilidad de la sanción, a lo menos cuando una técnica intransitiva le ofrezca ese espacio. En cambio, con una legislación transitiva, una extensión ad hoc, aunque se haga previsible, puede parecer más arbitraria, en la medida que el legislador no parece haber buscadoni dejado abierta la puerta ala extensión la sanción a estas conductas auxiliares.

Y ¿cómo se puede dejar a salvo la previsibilidad de la sanción a quien, estrictamente hablando, no incurrió en la conducta literalmente contemplada por el legislador? ¿Es necesario que la Administración haga previsible estas conductas a través de reglamentos, dictámenes u otros actos semejantes? ¿O el hecho de que la conducta del ejecutor esté claramente señalada en la ley basta para que se entienda sancionable la de quien lo instruye a actuar de esa forma o colabora con él, así como la de quien actúa en lugar suyo o tiene un rol de supervisión de su conducta y no lo ejerce, facilitando así que la infracción se perpetre?

O debe entenderse, por el contrario, que las referencias legales, sobre todo si la técnica regulativa es transitiva -por ejemplo, describiendo claramente la conducta sancionable-circunscriben a tal punto las competencias sancionatorias que ni aun mediante reglamentos, instrucciones u otros actos administrativos es posible extender su campo de aplicación a los otros intervinientes?

El derecho penal cuenta con reglas legales y la dogmática penal ha desarroIlado doctrinas jurídicas que permiten determinar el círculo de intervinientes sancionables con relativa certeza, sin lesionar el principio de legalidad. Pero ya hemos visto que las exigencias de legalidad de las infracciones administrativas no son tan elevadas como las de la legalidad de los delitos. Sin embargo, sí demandan previsibilidad de la sanción, dentro del marco fijado por el legislador y de los fines que éste persigue.

En los próximos apartados se examinará, teniendo en cuenta la diferencia entre las exigencias impuestas por el principio de legalidad en una y otra rama del derecho, si acaso las preguntas que guían este trabajo deben responderse, en el campo del derecho sancionatorio administrativo, de forma también diferente, o si más bien de forma similar a como se responderían en el campo del derecho penal.

Las peculiaridades de la materia aconsejan distinguir las preguntas más básicas relativas a la legalidad de la sanción a los partícipes -cómplices o inductores- (2.2.), de las más específicas referidas a la legalidad de la sanción a quienes, sin ser -aparentemente- destinatarios de la norma administrativa actúan en lugar de otro que sí lo es, así como a la legalidad de la sanción a los superiores o jefes que, sin incurrir -aparentemente- en la infracción, permiten que sus empleados lo hagan, sea dolosamente, sea por falta de supervisión adecuada (2.3.). 
En cada caso interesará, en primer lugar, la cuestión de política sancionatoria referida a si los intervinientes de primer orden son alcanzables por la potestad sancionatoria de la Administración, en todos los casos, y sin infringir la legalidad administrativa. Además, en segundo lugar, también interesa indagar-aunque con menos detenimiento- si acaso quedan sujetos a dicha potestad sancionatoria los intervinientes secundarios.

\section{2. ¿Quiénes incurren en una infracción administrativa?}

El derecho penal distingue entre los autores de un delito y los partícipes (inductores y cómplices). A estos últimos destina reglas especiales, sin las cuales, de acuerdo con la opinión aun dominante, partidaria de un concepto restrictivo de autor, ${ }^{45}$ no sería posible sancionarlos; reglas que además establecen un trato privilegiado, a lo menos para ciertos efectos. Por ejemplo, el ordenamiento jurídico chileno considera una pena más baja para los cómplices, y no sanciona las formas imperfectas de participación (tentativa de complicidad o de inducción, complicidad o inducción frustradas) ni tampoco, en principio, la participación en la participación (por ejemplo, al inductor de un cómplice o al cómplice de un inductor). ${ }^{46}$

Pero el tratamiento diferenciado entre autor y partícipes, que debemos especialmente a los desarrollos del derecho penal alemán, precisamente ha sido relativizado en el derecho sancionatorio administrativo, que ha intentado prescindir de la distinción, al introducir un concepto unitario (y extensivo) de autor. ${ }^{47}$

Un breve examen de la polémica entre ambas concepciones, en el campo de la dogmática penal, da luces sobre las alternativas interpretativas disponibles para el derecho sancionatorio administrativo.

\section{a. Legalidad penal en la polémica entre concepto restrictivo y concepto unitario (y extensivo) de autor}

\section{a.1. Concepto restrictivo de autor}

Como se dijo, de acuerdo con una opinión dominante en el derecho penal continental europeo, la exigencia de que los delitos se encuentren determinados

\footnotetext{
45 Infra, las referencias incluidas en a.1, en este apartado 2.2.

46 Estas restricciones son consecuencia del principio de accesoriedad de la participación respecto de la autoría, principio que, con todo, admite excepciones. Una explicación general de la cuestión y de sus excepciones en Couso (2013), pp. 623 y ss. En el derecho alemán, con todo, si bien tampoco son punibles ninguna de esas hipótesis por sí mismas, sí se admite que pueden constituir casos de complicidad en la medida que de hecho representan una cooperación al hecho; JAKOBS (1995), Apartado 22, nm 30; Roxin (2003), § 26, nm 178.

47 Infra, b, en este apartado 2.2.
} 
en la ley supone también la de que la ley precise las formas de intervención delictiva que resultan sancionables. Así, quien convence a otro de que perpetre un delito o lo auxilia para que lo perpetre sólo sería sancionable, entonces, en la medida que la ley considere expresamente esa posibilidad ${ }^{48}$. Y, si bien esto es más discutible, una aplicación estricta de lo que se conoce como el concepto restrictivo de autor también exigiría un apoyo legal expreso para sancionar al que -en calidad de autor mediato- perpetra el delito valiéndose de otra persona que opera como su instrumento, o para sancionar a quienes, sin realizar cada uno por su cuenta completamente el hecho, sí lo realizan conjuntamente, efectuando cada uno una contribución relevante: coautores. ${ }^{49} \mathrm{El}$ derecho penal

\footnotetext{
48 Así, en Chile, por todos, Cury (2005), pp. 623, 597, quien, además, entiende que ello se desprende del hecho que cada tipo penal se refiere únicamente al comportamiento del autor ejecutor individual, de modo que las cláusulas generales de incriminación a cómplices e inductores (y a coautores y autores mediatos) serían cláusulas "de extensión de la pena", justamente a hechos distintos de los tipificados en la ley como hechos de autor, constituyéndose en "tipos complementarios" (ibíd., pp. 483-584). Esta concepción es también ampliamente dominante en Alemania; Roxin (2003), § 25 nm 5-6. También parece posible sostener que el castigo de un cómplice o un inductor (así como el de los coautores y del autor mediato) sólo es procedente si una cláusula legal expresa lo permite, sin suscribir la tesis de que los tipos penales describen y sancionan el comportamiento del autor individual, sino sosteniendo que son "neutros", y que la imputación del respectivo injusto típico, sin embargo, recién ocurre en virtud de "tipos de imputación" legales contenidos en tales cláusulas; así, MAÑALICH (2009), p. 127 y ss., siguiendo en lo esencial el planteamiento de BLor (1985), 293 y ss. MAÑALICH (2014b), p. 245, nota 68, rechaza, por ello, la idea de que los tipos de la Parte Especial sean "tipos de autor", pues precisamente son neutrales y sirven como objeto de imputación común, tanto a autores como a partícipes, si bien la imputación opera de distinta forma en cada caso (respectivamente, como lesión primaria de un deber de evitar directamente una acción principal; o como lesión secundaria de un deber de evitar una acción auxiliar de aquella). Con todo, es perfectamente posible concebir que el tipo de imputación, para el autor ejecutor individual, está contenido en el respectivo precepto de la Parte Especial, sin afectar el carácter neutro del comportamiento típicamente antijurídico, en relación con las formas de intervención, comportamiento que sigue siendo un objeto de referencia de los tipos de imputación de los cointervinientes, que estarían contenidos, ellos sí, en las cláusulas generales de la Parte General del Código Penal. Ello es posible si se entiende, como lo hace, por ejemplo, Silva Sánchez (1992), pp. 392, 406, 415 y ss., que los preceptos de la Parte Especial tienen, uno junto al otro, un aspecto de antinormatividad o del tipo de injusto penal -como "tipicidad ex ante"- y un aspecto de imputación o del tipo punible-como "tipicidad ex post".
}

49 Sobre la necesidad de cláusulas de incriminación expresa para poder sancionar la autoría mediata y la coautoría, y sobre los límites que el tenor de las mismas imponen, Couso (2012), pp. 123-124. Sin referencias directas a la necesidad de un apoyo legal expreso, pero sugiriéndola fuertemente a partir del tópico de la "función constitutiva de la autoría mediata", MAÑAlich (2010), pp. 390 y ss. Por su parte, ya CURY (2005), pp. 597, 600 y 604, parece entender que la responsabilidad del autor mediato requiere de cláusulas expresas de incriminación. Pero la necesidad de este tipo de cláusulas parece ser descartada por quienes se decantan por un criterio puramente material de definición de la autoría, como el dominio del hecho, sin reconocer límites provenientes de la estructura (o tenor) de la norma de sanción (conforme a la cual, sólo sería directamente punible en base a ella quien realiza precisamente la conducta descrita por el tipo, que ciertamente no consiste en "forzar a otro" a ejecutar el respectivo comportamiento, sino ejecutarlo él mismo). En tal sentido, acogiendo un concepto restrictivo de autor 
satisface esta exigencia con diversas cláusulas generales de incriminación de esas formas de intervención, incorporadas en la Parte General del Código Penal, que amplían el ámbito de lo punible hacia esos comportamientos (causas de extensión de la pena). ${ }^{50}$ La afirmación de que la respectiva incriminación de la Parte Especial sólo permite sancionar al autor (ejecutor individual) y que sin aquellas cláusulas de la Parte General no es posible sancionar a los demás intervinientes, constituye la esencia del así llamado concepto restrictivo de autor. ${ }^{51}$

El concepto restrictivo de autor es una consecuencia de la distinción material entre autor y los demás intervinientes. Sólo quien reconoce una diferencia entre ellos puede afirmar que la norma que permite sancionar al primero no basta, por sí sola, para sancionar a los segundos, y que la sanción de estos hace necesaria una cláusula complementaria. El reconocimiento de aquella distinción también es una condición de posibilidad del principio de accesoriedad de la participación respecto de la autoría ${ }^{52}$, un importante principio, ampliamente aceptado en el derecho penal, conforme al cual la responsabilidad penal de los partícipes (cómplices o inductores) supone como condición necesaria que su intervención haya sido auxiliar respecto de un comportamiento perpetrado por otra persona, en calidad de autor, comportamiento que debe a su vez reunir determinadas características. ${ }^{53}$

La exigencia de legalidad de la infracción, entendida bajo un concepto restrictivo de autor, y aplicada al derecho sancionatorio administrativo "sin

que podría calificarse de moderado (y no uno estricto), para el cual la mención legal expresa sólo sería necesaria para la participación, pero no para la autoría mediata, Roxin (2006), p. 328; y JAKOBS (1995), apartado $25 \mathrm{~nm} 8$ (criticando al concepto restrictivo de autor entendido de modo "naturalístico", que excluye la autoría mediata, lo que no sería necesario si se concibe la ejecución del hecho como "responsabilidad por el resultado"). Es de interés también la construcción operada por la jurisprudencia holandesa, que, de forma paralela a la aplicación de la cláusula legal que incrimina el "hacer cometer" para los casos tradicionales de autoría mediata mediante la utilización de un instrumento no punible, amplió por la vía interpretativa el significado de la expresión legal "cometer", para aplicarla a casos de "autoría funcional" con utilización de intermediarios punibles, como ocurriría en las hipótesis de "autor detrás del autor", e incluso, de responsabilidad de la persona jurídica; en detalle, PoltTOfF LifSHITZ (2001), pp. 1247 y ss., quien además, al tratar del derecho chileno, sugiere que la punibilidad de la autoría mediata se funda en la cláusula (expresa) del artículo $15, \mathrm{~N}^{\circ} 2^{\circ}$, del $\mathrm{CP}$, si bien, no exactamente en el verbo "forzar", sino ya en el verbo "inducir" (que abarcaría, con ello, más que la mera instigación).

50 Roxin (2003), § 25 nm 5.

51 Ibídem.

52 Es una condición necesaria, pero no suficiente, pues también es posible reconocer la diferencia entre autor y partícipes y no definir la responsabilidad de estos de forma accesoria al comportamiento de aquél. Así ocurre con el concepto unitario de autor en sentido funcional; infra, a.2, en este apartado 2.2.

53 Normalmente se exige que se trate de un comportamiento típico y antijurídico (accesoriedad media), que a lo menos se encuentra en fase de tentativa. Sobre el principio de accesoriedad, sus consecuencias y límites o excepciones, Couso (2013), pp. 623 y ss. 
matices", conduciría, en el Caso Cascadas, a excluir de la sanción a Ponce Lerou, por la realización de operaciones con sociedades relacionadas, así como a Larraín Vial por la celebración de transacciones ficticias con valores, dado que ninguno de ellos contaba con la calidad especial exigida por la disposición que describe la infracción (ser "sociedad" o ser parte en la transacción,como comprador o vendedor) y, además, la ley no contempla una causa de extensión de la sanción para los inductores -en el primer caso- o para lo cómplices -en el segundo caso. Ahora bien, la sanción a Ponce Lerou por su responsabilidad "vicaria" a título de director de la sociedad, aun sin intervención directa en los hechos (sin que haya efectuado las transacciones ficticias) podría justificarse si se adhiere a la así llamada teoría de los delitos de infracción de deber, que no requiere de parte del autor el tipo de intervención inmediata y material que suele caracterizar su conducta, sino que se conforma precisamente con que la afectación del bien jurídico se haya producido a través de su infracción de un deber especial. ${ }^{54}$

Por lo que respecta al Caso Blackout, esa forma de entender la exigencia de legalidad de la infracción conduce también a excluir la sanción a Endesa. La posibilidad de afirmar su responsabilidad sancionatorio-administrativa supone, por cierto, la aplicación de un paradigma distinto del tradicional en el derecho penal, para el cual la responsabilidad de las personas jurídicas es excepcional, y requiere condiciones especiales..$^{55}$ Pero aun superada esta dificultad, que para la legislación administrativa sectorial ostensiblemente no es tal, ${ }^{56}$ bajo el concepto restrictivo de autor sólo sería posible sancionar a Endesa si los órganos que la representan incurren en la infracción, que por una ficción legal luego se entiende perpetrada por la empresa. Pero precisamente el caso es que estos órganos no aparecen como los autores de la actuación defectuosa del funcionario que dio origen al blackout. Imputar a los órganos directivos de Endesa la actuación del funcionario exige invocar algún título válido que permita extenderles la infracción (y la sanción) de éste: sea a título de cómplices (por omisión) suyos, sea a título de superiores jerárquicos negligentes en su supervisión, títulos que, sin una cláusula expresa de extensión de la sanción,

\footnotetext{
54 Y la monografía -aparecida por primera vez en 1963- de Roxin (2006), pp. 353 y ss., 367 y ss. Actualmente, Roxin (2003), § 25 nm 267 y ss. En Chile, por todos, CURY (2005), pp. 616 y ss., 619-620, refiriéndose también al tratamiento del problema en Alemania. Para una crítica reciente, a partir de postulados liberales y garantistas, a los delitos de infracción de deber y, en particular, a su pretensión de afirmar autoría del especialmente obligado, cualquiera que haya sido la forma de su conducta, MAÑALICH (2012), pp. 362, 359 y ss.

55 Para una visión panorámica del sistema de la chilena, HeRnÁnDEZ (2010), pp. 216 y ss.

56 En la medida que la propia ley establece deberes para las empresas concesionarias, y considera sanciones para el caso del incumplimiento de tales deberes.
} 
sería difícil reconocer. Por cierto, aun sin tal cláusula de extensión, una alternativa que se abre para la sanción a Endesa es la aplicación de la ya referida teoría de los delitos de infracción de deber, conforme a la cual, en este caso, las "empresas concesionarias" aparecen como destinatarias de un deber especial en el marco de la Ley General de Servicios Eléctricos (asegurar la interconexión y operatividad del sistema eléctrico), y deben por ello ser consideradas autoras de las contravenciones en las que intervinieren de cualquier modo (incluso por omisión), infringiendo su deber, por más que no hayan ejecutado directa y materialmente la conducta.

\section{a.2. Concepto extensivo y unitario de autor}

En el derecho penal, al concepto restrictivo de autor se opone el concepto extensivo de autor, conforme al cual los preceptos de la Parte Especial, vistos en sí mismos, perfectamente podrían servir de base para la sanción de cualquier interviniente, Ilámesele autor o partícipe. Según quienes defienden el concepto extensivo de autor, incluso en las legislaciones que contemplan cláusulas en la Parte General para dar un tratamiento penal distinto a los partícipes -por ejemplo, para rebajar la pena al cómplice-, estos "partícipes" son materialmente autores, cuya conducta es subsumible, prima facie, en los respectivos tipos de la Parte Especial, pero lo que ocurre es que aquellas cláusulas, como lex specialis, se aplican con preferencia frente a la norma de la Parte Especial, determinando "sacar" del ámbito de esta última el caso de los partícipes, para tratarlo conforme a la regla de la Parte General. ${ }^{57}$

La defensa de un concepto extensivo de autor supone, como se ve, la adhesión al asíllamado concepto unitario de autor, ${ }^{58}$ que justamente niega que haya una diferencia material entre el autor (ejecutor individual) y los demás intervinientes. Así lo sostiene la versión más radical de esta concepción -el concepto unitario de autor en sentido formal-, para la cual son autores todos quienes contribuyan causalmente a la producción del resultado delictivo (también, por ejemplo, entregando al ejecutor los medios, o convenciéndolo de que ejecute el hecho), y todos merecen, en principio, el mismo tratamiento y quedan sujetos a un mismo marco penal, siendo improcedente una distinción conceptual

57 Roxin (2003), § $25 \mathrm{~nm} 4$.

58 Similar en esto Rotsch (2009), p. 282, si bien afirmando más bien que el concepto extensivo de autor "conduce por la fuerza a" ("führt [...] zwingend zu") un concepto unitario de autor. A mí me parece que, lógicamente, es más clara la tesis que formulé en el texto principal, es decir, la tesis conforme a la cual quien sostiene un concepto unitario de autor (=todos quienes causen el resultado son autores), debe suscribir un concepto extensivo de autor (=todos ellos-los causantes-son sancionables conforme al respectivo precepto de la Parte Especial, salvo si una cláusula de la Parte General, como lex specialis, obliga a tratar a alguno de ellos de forma distinta). 
entre autores y partícipes. ${ }^{59}$ Por su parte, para el concepto unitario de autor en sentido funcional, si bien todos los intervinientes son autores, sujetos al mismo marco penal, es necesario mantener la distinción conceptual entre autores y partícipes para hacer operativas ciertas decisiones valorativas del legislador, como la de dejar fuera del campo de la punibilidad ciertos comportamientos que no merecen o no necesitan ser objeto de sanción penal (por ejemplo, la tentativa de complicidad). ${ }^{60}$ Ello supone, en realidad, un reconocimiento de la diferencia material y conceptual entre el autor y los demás intervinientes.

El concepto unitario de autor (en cualquiera de sus versiones) prescinde del principio de accesoriedad, afirmando que cada interviniente responde por su propio injusto y su propia culpabilidad, sin depender para ello de la responsabilidad de otro (en particular, de aquel a quien la concepción diferenciadora calificaría como "autor"), ${ }^{61}$ incluso, con independencia de cualquier cualidad de la conducta de ese otro. ${ }^{62}$

El concepto unitario de autor, al igualar las contribuciones causales hechas por cada interviniente, y sancionar cada una de ellas con independencia de (las características de) las contribuciones de los demás, simplificaría la aplicación del derecho, sobre todo atendiendo a lo complejo de la distinción entre autor y partícipe, que ha estado sujeta a una interminable polémica doctrinaria, bastante alejada de las necesidades y posibilidades de los tribunales que han de aplicar el derecho. ${ }^{63}$ Esas podrían ser razones a favor de la adopción de un concepto unitario y un concepto extensivo de autor en el derecho sancionatorio administrativo. De hecho, en el Caso Cascadas, la adopción de un concepto extensivo y de uno unitario de autor llevaría a sancionar, sin problemas, a Ponce Lerou, por las operaciones con empresas relacionadas, y a Larraín Valdés por las transacciones ficticias, sin importar que ninguno de ellos haya incurrido en las respectivas conductas. Cada uno de ellos sería autor de la infracción, en la

\footnotetext{
59 Rotsch (2009), pp. 133 y ss., refiriéndose a la distinción propuesta por KIENAPFEL entre la concepción formal y funcional (o material) del concepto unitario de autor. También Blor (1985), p. 150.

60 Rotsch (2009), pp. 138 y ss.

61 Rotsch (2009), pp. 133 y 139.

62 En palabras de Jаковs (1995), apartado $21 \mathrm{~nm} 5$, sin importar si dicha conducta es "dolosa, imprudente, inevitable; culpable, inculpable".

63 en tal sentido, Rotsch (2009), pp. 1-4, 421 y ss. y 484-486, abogando, a lo largo de esta obra, por una concepción normativo-funcional de injusto penal tendencialmente monista (sin perjuicio de la posibilidad conceptual de distinguir entre competencia inmediata y competencia mediata por la afectación del bien jurídico), a partir de la cual la imputación de responsabilidad opere con prescindencia de la diferenciación entre autores y partícipes, pero también superando el dogma causal en que se fundó el concepto unitario de autor, y que afirme autoría, por igual, de todos quienes realizan una contribución, no meramente causal, sino que satisfaga además las exigencias de la teoría de la imputación objetiva.
} 
medida que contribuyó causalmente con la realización de la misma. Lo propio podría decirse de Endesa en el Caso Blackout, en la medida que su "propia" omisión (identificable - de acuerdo con la ficción legal asumida por la ley sectorial- con la omisión de los órganos directivos) de ejercer una supervisión adecuada sobre el comportamiento del funcionario -o de adoptar planes generales de prevención de ese tipo de fallos- está causalmente conectada (a lo menos en el sentido de una "causalidad hipotética") con el comportamiento del funcionario que materialmente desencadenó el blackout.

\section{a.3. Garantías penales y concepto extensivo y unitario de autor}

Pero, $i s e$ encuentran el concepto restrictivo y el concepto unitario de autor a disposición del aplicador del derecho, como una cuestión de simple preferencia, cualquiera sea la forma como está estructurada la ley?

En el derecho penal ello es muy dudoso. Las mejores razones llevan a concluir que a lo más, y bajo ciertas condiciones, el concepto unitario de autor podría acogerse, de lege ferenda. En cambio, como propuesta interpretativa de lege lata, aplicable a todas las incriminaciones, sin importar su tenor, es una concepción incompatible con un principio fundamental del derecho penal: justamente, el ya tan mentado principio de tipicidad.

Al concepto unitario de autor se le critica, en efecto, que la pretensión de tratar como autor del delito también a quien sólo de forma mediata ha puesto una condición necesaria de su ocurrencia sería incompatible con el principio de tipicidad, pues es lingüísticamente forzado, por ejemplo, afirmar que quien aconseja a otro imputar a un tercero un delito determinado pero falso está, también él mismo, realizando dicha imputación, necesaria para ser autor del delito de calumnia. ${ }^{64}$

Esa manera de forzar el lenguaje ha sido criticada en el ámbito del derecho penal internacional, por constituir una infracción del principio del fair labelling ("etiquetamiento justo"). ${ }^{65}$ Originalmente, este principio ${ }^{66}$ sólo exigía que la imputación fuera lo suficientemente diferenciada en relación con el tipo delictivo imputado, en concordancia con la efectiva disposición subjetiva del autor. ${ }^{67}$ Pero

64 Así, JAKOBS (1995), apartado 21 nm 6.

65 Ya NerSESSIAN (2006), pp. 81-82; también JACKSON (2016), pp. 13-14.

66 Formulado por Williams (1983), p. 85, si bien recogiendo en lo esencial la noción de representative labelling de AsHWORTH.

67 Objetando así, por ejemplo, la aplicación de la doctrina de la transferred intent, que permite en ciertos casos imputar asesinato-murder-a quien tan sólo ha dado muerte a otro de forma imprudente; Chalmers y Leverick (2008), p. 219. 
posteriormente se ha admitido que el principio exige que el efectivo injusto del hecho (wrongdoing) sea etiquetado o señalizado por la ley con un suficiente grado de especificidad, de modo de distinguir entre infracciones de diverso nivel de gravedad. ${ }^{68}$ El principio de fair labelling se funda en la necesidad de que el sistema de justicia comunique correctamente al ofendido, a la víctima y al resto de la sociedad, la naturaleza y grado de injusto, para efectos de determinar una sanción proporcionada, de evaluar la gravedad de los antecedentes penales previos de un acusado, de clasificar apropiadamente a los internos en la prisión, así como para reflejar correctamente los patrones valorativos de la comunidad. ${ }^{69}$ Y justamente ello no ocurriría si a cualquier individuo que ha tenido influencia causal en el delito (incluso omisiva), se le considera públicamente como su autor, trátese de un cómplice, un superior jerárquico negligente en la supervisión de sus subordinados, del miembro de un grupo que acuerda un plan delictivo de menor gravedad, que luego se le va de las manos al ejecutor, etc., cuyos comportamientos pueden diferir en una medida significativa en su nivel de gravedad, en comparación con los del autor.

Por último, imputar a quien no ha incurrido directamente en el comportamiento descrito por la ley, el delito perpetrado por un tercero, sin correspondencia con su propia responsabilidad, puede afectar el principio de culpabilidad, sea porque el primero no es en absoluto responsable de que el tercero haya incurrido en esa conducta, sea porque, aun siendo responsable por ello, su culpabilidad es menor - por ejemplo, negligente- a la que se ve reflejada por el delito que se le imputa -si, siguiendo el mismo ejemplo, se le imputa el mismo delito perpetrado por el tercero, a título de dolo. ${ }^{70}$ Esta desproporción puede darse ciertamente al extender la calidad de autor a cualquiera que sólo haya tenido un (tenue) influjo causal en el hecho. ${ }^{71}$

\section{a.4. Legislación penal moderna: ¿superación tendencial de la dicotomía?}

Sin embargo, esas críticas no serían aplicables a los tipos penales redactados de tal forma que, sin forzar el lenguaje, admiten -incluso exigirían-ser entendidos como tipos de autor unitario, lo que ocurriría, como ha argumentado Rotsch, en buena parte la legislación penal moderna, como la criminalidad organizada o de empresa -que justamente tiende a igualar a diversos tipos

68 AshWORTH y HORDER, (2013), pp. 77-79.

69 AshwORTH y HORDer, (2013), pp. 77-78.

70 Así, Robinson (1984), pp. 619 y ss.

71 Robinson (1984), p. 635. 
de intervinientes- e incluso en importantes sectores de la legislación penal clásica. ${ }^{72}$

Así, por ejemplo, el delito de tráfico de estupefacientes, en la generalidad de las legislaciones modernas, sanciona de la misma forma una muy amplia gama de formas de intervención en la empresa criminal dirigida a producir y distribuir drogas, sin las distinciones habituales, consagrando así, de hecho, un sistema de autor unitario. ${ }^{73}$ Algo similar ocurriría con los tipos de asociación criminal y de lavado de activos. ${ }^{74}$

Pero, en fin, también en tipos clásicos, como los delitos contra la paz o la seguridad del Estado, contra los órganos constitucionales, contra la transparencia de las elecciones, contra el orden público, contra la competencia y contra el medioambiente, entre otros, estarían concebidos y redactados por el legislador de tal manera que diversas formas de intervención, incluyendo aquellas que en otros casos podrían ser propias de un partícipe, podrían quedar igualmente cubiertas por el respectivo tipo, como comportamientos de autor. ${ }^{75}$

Esta relativa apertura de tales descripciones típicas, que dejarían espacio para subsumir en ellas comportamientos de muy diversa índole que, en sí mismos, la concepción tradicional calificaría como casos de mera participación, se explicaría, según Rotsch, por cuatro tendencias apreciables en la técnica legislativa contemporánea: ${ }^{76}$

1) la autorificación (Vertäterschaftlichung) de conductas de participación, como ocurre por ejemplo cuando, en el mismo nivel que la ejecución de las conductas que inmediatamente afectan el bien jurídico, se tipifica la que consiste en prestar los medios con que ello se lleva a efecto (en Chile, por ej., la facilitación del lugar de reunión de los miembros de una asociación ilícita, en el art. 294 del CP);

72 Así, con detalles, en relación con la legislación alemana, Rotsch (2009), pp. 205 y ss. y 209 y ss. En este lugar no viene al caso una valoración global de la tesis de Rotsch -quien es crítico tanto del concepto unitario de autor como de la diferenciación entre autoría y participación- que exigiría la revisión de un amplio grupo de delitos que, por lo demás, pueden estar configurados de manera distinta en diversos ordenamientos jurídicos. Pero sí parecen sugerentes algunos ejemplos, sobre todo de la legislación penal moderna.

73 Así, en relación con la legislación alemana, Rotsch (2009), p. 207. Sin la radicalidad del planteamiento de RoTsCH, también un partidario del modelo diferenciado de autoría y participación, como lo es Roxin (2003), § $25 \mathrm{~nm} 7$, reconoce esas tendencias hacia la unificación del concepto de autor en algunos de esos campos de la legislación penal moderna.

74 Rotsch (2009), pp. 206-207, refiriéndose a la legislación alemana, pero con ejemplos que, en este caso, son aplicables en buena medida a otras legislaciones, como la chilena.

75 Rotsch (2009), pp. 211 y ss.

76 Con detalles, Rotsch (2009), pp. 281 y ss. 
2) la equiparación de la tentativa con la consumación, pues en relación con la tentativa las formas de afectar -poniendo en peligro- el bien jurídico se amplían mucho, siendo artificial la distinción entre las que configurarían autoría y las que configurarían participación (por ej., la tentativa de robo, en el art. 450 del CP);

3) la tipificación de meros actos de preparación, pues, al alejar la acción típica del bien jurídico protegido, se amplía el círculo de potenciales destinatarios de la norma y, con ello, también se amplía el círculo de acciones subsumibles (así, la fabricación, expendio o tenencia de ganzúas, en el art. 445 del CP, o la acción de guardar estupefacientes que se han de traficar, en el art. $3^{\circ}$, inc. $2^{\circ}$, de la Ley de Drogas No 20.000); y

4) la ulterior abstracción del bien jurídico protegido, pues al alejar el bien jurídico de la acción típica, también se difumina la posibilidad de distinguir materialmente comportamientos de autor y de partícipe, de entre todos aqueIlos que son idóneos para afectar tal bien jurídico (así, por ej., en la acción de alzarse a mano armada contra el Gobierno lealmente constituido, del art. 121 del CP; o propagar indebidamente organismos, productos, elementos o agentes "susceptibles de poner en peligro la salud animal o vegetal", en el art. 291 del CP; o en la acción de ocultar o disimular "de cualquier forma" el origen ilícito de los bienes, en el art. 27, a), de la Ley $\mathrm{N}^{\circ}$ 19.913).

Sin embargo, si se observa más detenidamente la estructura de los tipos en estos casos, la afirmación de que ellos dan lugar a un sistema de autor unitario oculta fenómenos y proposiciones bien distintas.

Así, en las hipótesis de la autorificación de formas de participación, ocurre sencillamente que el legislador incluyó en un tipo penal, de forma expresa, y equiparándolas a las hipótesis de autoría, diversas conductas que, bajo un modelo diferenciado de formas de intervención, calificarían como hipótesis de participación; de modo que afirmar que de ese modo el legislador acogió un sistema de autor unitario, en realidad, simplemente consiste en una proposición más bien descriptiva, conforme a la cual, en el listado de conductas incluidas en el tipo es posible reconocer casos de ejecución del hecho, que una teoría diferenciadora calificaría de autoría, junto a casos que la misma teoría calificaría de participación. Así, la recepción de un sistema de autor unitario es sólo relativa a la mayor o menor amplitud del listado de hipótesis incluidas en el tipo; muy restringida, por ejemplo, en el caso del art. 294 del CP (sólo queda equiparada a la autoría la facilitación del lugar de reunión de los miembros de una asociación ilícita, pero no la vigilancia externa que se ofrecerá al recinto ${ }^{77}$ );

77 Nótese que la mención del art. 294 del CP a la facilitación de "medios e instrumentos" no está referida a los que están al servicio de la asociación, sino a los que servirán directamente para perpetrar los 
bastante más amplia -pero no necesariamente completa- en el caso del art. $3^{\circ}$, inc. $2^{\circ}$, de la Ley de Drogas (que equipara a la autoría un gran conjunto de acciones auxiliares, pero no todas las imaginables). Con ello, la unificación entre autoría y participación no es necesaria o conceptual, sino contingente o de técnica legislativa y, casi por definición, parcial, pues siempre será posible imaginar comportamientos no incluidos en el listado, que seguirán siendo dables distinguir como casos de complicidad, que deben ser tratados de forma diferenciada, conforme al art. 16 del CP. ${ }^{78}$

En cambio, en relación con las restantes tres tendencias referidas por Rotsch, ocurre que el legislador tipificó un determinado comportamiento cuya relación con el bien jurídico protegido, por las diversas razones ahí señaladas, aparece como más distante que en los casos de autoría reconocidos por un modelo diferenciado, respecto de un hecho consumado que afecta un bien jurídico individual; de modo que afirmar que en esos otros tres casos el legislador acogió un sistema unitario de autor consiste en una proposición más claramente interpretativa, conforme a la cual dentro de un tipo penal así definido es posible, teleológicamente, incluir una amplia gama de comportamientos, incluyendo tanto aquellos que un modelo diferenciado consideraría de autoría como los que calificaría de participación.

Desde ese punto de vista, la distinción entre autores y partícipes en esos delitos no es posible, o bien, sería muy artificial si se interpretan ellos teleológicamente para determinar qué acciones representan un atentado al bien jurídico relevante para el respectivo tipo. Así, por ejemplo, no tendría sentido decir que sólo se "alzan a mano armada" quienes efectivamente portan las armas y no, en cambio, el general que da la orden a sus huestes de tomar el edificio de Gobierno por las armas ${ }^{79}$, para tratar a éste como inductor. Asimismo, tampoco tendría sentido la afirmación de que sólo guarda los estupefacientes el que materialmente los ingresa en la bodega donde se les almacenará, y no el dueño de la bodega que la facilita para ese fin; y sería a lo menos dudosa la pretensión de que sólo propaga los elementos peligrosos para la salud animal o vegetal el que

delitos-fin de la misma, de modo que no puede verse ahí una amplia equiparación de comportamientos de complicidad (con la asociación) con los de autoría.

78 Ello explica, por ejemplo, que MuÑoz CONDE (2015), pp. 581-582, refiriéndose al delito de tráfico de drogas en el CP español, afirme que se acoge un concepto unitario de autor, pero admita al mismo tiempo la posibilidad de reconocer una complicidad, castigada de acuerdo con las reglas generales, en las formas de cooperación que no aparecen expresamente tratadas por la ley como (autoría de) tráfico.

79 Y nótese que en este caso, el recurso a una autoría mediata por utilización de aparato organizado de poder no está a disposición, no sólo de la doctrina contraria a reconocer autoría en esta constelación, sino tampoco de todo aquel sector que exige, para admitirla, que el aparato organizado se encuentre apartado del Derecho (rechtsgelöst); Roxın (2006), pp. 249 y ss., 716-717. 
materialmente abre la llave de paso desde el camión que porta fluidos peligrosos para verterlos en el curso de agua, y no el empresario que envió el camión. ${ }^{80}$ Así, la recepción de un sistema de autor unitario, en estos casos, alude a una unificación conceptual entre todos los diversos comportamientos subsumibles en una única hipótesis típica, deducida de consideraciones semánticas -sobre el verdadero sentido del tipo- en gran medida teleológicas -referidas al fin de protección de la norma- de modo que no tendría caso pretender que sólo quedarían equiparadas a la autoría hipótesis de complicidad que el legislador expresamente menciona, debiendo tratarse a las demás de forma diferenciada, de acuerdo con el art. 16 del CP.

Como se ve, la afirmación de que en el primer caso el legislador acoge un sistema de autor unitario, siendo descriptiva, y relativa a la mayor o menor extensión del listado incluido por aquél, no es problemática, y es bastante trivial, de hecho. En cambio, la proposición referida a los demás casos, de que ellos dan cuenta de la recepción de un sistema de autor unitario, es potencialmente mucho más fructífera, pero, al mismo tiempo, es ciertamente discutible. Pues con esa proposición no se está sugiriendo simplemente que un concepto como propagar es semánticamente más amplio que, por ejemplo, el de verter, sino que se estaría al mismo tiempo alegando que, atendida la abstracción del bien jurídico operada por el legislador, al referir la primera conducta a los peligros para la salud animal o vegetal las diversas formas de intervención en el hecho quedan equiparadas y todas ellas pueden calificarse de propagación de elementos peligrosos. Una conclusión como esa no sería difícil de alcanzar si se castigase simplemente al que pusiere en peligro la salud animal o vegetal, pero es claro que tal descripción no satisfaría las exigencias del mandato de determinación de los tipos penales. La cuestión es si, justamente, una descripción más precisa, como la propagación de elementos peligrosos para la salud animal o vegetal, no obliga a distinguir acciones principales de acciones auxiliares, bloqueando la posibilidad de argumentar la recepción de un sistema de autor unitario en un tipo de tal tenor.

Precisamente una distinción de ese tipo -entre acciones principales y auxiliares- parece oponerse a la afirmación de una unificación conceptual entre

\footnotetext{
${ }^{80} \mathrm{Y}$ ello aun cuando se conciba al delito como uno de dominio, que no requiere en el infractor de la norma la lesión de un deber especial. En cambio, si como ocurre en el derecho administrativo ambiental, es posible concebir al incumplimiento de las normas administrativas medioambientales como una infracción con la estructura de los delitos de infracción de deber, entonces el único autor sería el empresario "titular" de la fuente emisora, y el operario que realiza el vertido aparecería como mero cómplice, supra, a.1, en este apartado 2.2. Cfr. también, Politoff LifsChitz (2001), p. 1277, quien, por razones de justicia y de utilidad preventiva, considera que en estos casos no tiene sentido hacer recaer toda la responsabilidad sobre los obreros, siendo necesario ir más atrás, para hacer responder incluso a la persona jurídica por cuya cuenta y riesgo los obreros trabajan.
} 
autores y partícipes, en los tres casos más discutibles, de entre los propuestos por Rotsch. Así, por ejemplo, Mañalich ${ }^{81}$ afirma una distinción categorial entre autores y partícipes a partir de la semántica de los tipos penales y la lógica de la adscripción (y la descripción) de las acciones. En apretada síntesis, desde esta perspectiva, de entre todas las acciones que representan una contribución causal a la realización del hecho típico (incluidas, por ejemplo, la de convencer a otro para que ejecute el hecho, y aun la de facilitarle los medios con que lo hará), sólo fundamentan responsabilidad a título de autoría las acciones principales, esto es, aquellas que "por sí mismas" - sin necesidad de complemento a través de una acción distinta, ejecutada por un tercero- satisfacen la descripción del tipo de acción sujeta a prohibición. ${ }^{82}$ El tipo de acción sujeta a prohibición se identifica semánticamente a partir del tipo penal y, en el caso de los delitos de resultado puros, consiste en la "producción" de una "modificación perjudicial del estado" del objeto de protección de la norma. ${ }^{83} \mathrm{Y}$ se considera autor de tal acción a quien "en el momento relevante" para evitar la realización del tipo, contaba con la oportunidad, a través de su propio comportamiento -sin necesidad de que otro actúe o deje de actuar- de seguir la norma, es decir, de omitir una acción productora de aquella modificación perjudicial, o de infringirla. ${ }^{84}$ En cambio, son acciones auxiliares, que fundamentan responsabilidad a título de partícipe, aquellas que por sí mismas no satisfacen la descripción del tipo de acción sujeta a prohibición, ${ }^{85}$ pues por sí mismas no producen una modificación perjudicial del estado en que se encuentra el objeto protegido por la norma, de modo que quien las ejecuta no se encontraba, en el momento relevante para evitar aquella modificación, en situación de impedirla a través de la omisión de su acción. ${ }^{86}$

\footnotetext{
81 Mañalich (2014a), pp. 71 y ss., 86 y ss., desarrollando desde el punto de vista de una teoría de la acción el planteamiento que ya en MAÑALICH (2009), pp. 127 y ss. había esbozado desde la teoría de las normas.

82 Lo propio vale, invirtiendo los términos, para la identificación de acciones de autoría en la omisión; es decir, ahí se trata de identificar acciones (omitidas) que por sí mismas satisfacen la descripción del tipo de acción que está sujeta a prescripción. MaÑaLICH (2014a), pp. 71 y ss.

83 MaÑalich (2014a), pp. 34, 35-36 (las cursivas están en el original).

84 Mañalich (2014a), pp. 72-73 y Mañalich (2010), p. 397, siguiendo el análisis de Von WRIGHT (1963), pp. 35 y ss. (la acción humana sólo tiene lugar cuando hay una oportunidad para que un agente produzca un cambio en el estado de cosas, que no ha de tener lugar por sí mismo) y 73 y ss. (las normas tienen como condición mínima de aplicación que el agente cuente con una oportunidad para la acción), y haciendo fértil tal análisis para la distinción entre acciones principales, constitutivas de autoría, y acciones auxiliares, constitutivas de participación.
}

85 MaÑalich (2014a), p. 73.

86 La distinción lógica entre acciones de uno y otro tipo podría adquirir, además, estatus valorativo relevante, para dar tratamiento diverso a autores y partícipes, a partir del principio de 
Una distinción de ese tipo, entre acciones principales y auxiliares impediría, por ejemplo, calificar como autor de propagación de elementos peligrosos para la salud vegetal o animal a quien facilita el camión en que se transportan, o calificar de autor de la acción de guardar los estupefacientes, con los que se ha de traficar, a quien facilita el candado con el que se asegurará la bodega donde se guardan.

Así, pese a que el tenor estructura y telos de los tipos penales puede tener incidencia en una mayor capacidad de los mismos para acoger en su interior, como comportamientos de autoría, formas de intervención que normalmente son consideradas hipótesis de participación, la exigencia de tipicidad se opone a la aplicación indiscriminada de un sistema de autor unitario.

\section{b. Legalidad sancionatorio-administrativa. ¿Concepto restrictivo o concepto unitario (y extensivo) de autor?}

Lo recién dicho vale para el derecho penal. Sin embargo, ya se ha fundamentado suficientemente la afirmación de que el principio de tipicidad, tal como se le conoce en el derecho penal, no tiene aplicación en el derecho sancionatorio administrativo. El principio de legalidad de las infracciones administrativas (o, para el TC, la aplicación de la tipicidad "con matices") se conforma con menos.

¿Con cuánto menos?

Recuérdese que las exigencias de la legalidad, desde la perspectiva del aplicador del derecho, pueden ser distintas según cuán específica o estricta es la ley al fijar los presupuestos de ejercicio de la potestad sancionatoria de la Administración. Si la ley no es transitiva, entonces el órgano administrativo puede ejercer la potestad sancionatoria respecto de una gama más o menos amplia de comportamientos, siempre que, en cumplimiento de las directivas de política pública fijadas por el legislador, haya desarrollado reglas -a través de diversos mecanismos de implementación de los estándares legales- que hagan previsible para el particular la posibilidad de sanción, y la entidad de ésta. En cambio, si la legislación respectiva es en alto grado transitiva, describiendo conductas precisas, entonces la exigencia de legalidad plantea al órgano administrativo aplicador del derecho exigencias similares a las que el principio de tipicidad impone a los jueces. ${ }^{87}$

autorresponsabilidad, que confiere primacía al comportamiento de aquellos cuya infracción de la norma se produce justamente porque en la situación concreta tenían el deber (y la oportunidad) de omitir una acción del primer tipo. Así, Mañalich (2010), p. 391, si bien fundamentando la primacía, en ese entonces, a partir de la "hipótesis naturalista" -provisoria- de responsabilidad personal, y primordial, por lo que se ha ocasionado directamente a través del propio cuerpo, de propia mano.

87 Salvo por la posibilidad excepcional, en los casos difíciles, de que el órgano administrativo extienda el ejercicio de la potestad sancionatoria a conductas no estrictamente señaladas en la ley, pero 
Por su parte, los argumentos que, en contra del concepto unitario y extensivo de autor, pueden desprenderse del principio de fair labelling, son extensibles al derecho sancionatorio administrativo sólo de forma muy limitada. En efecto, las funciones del fair labelling, reseñadas más arriba, ${ }^{88}$ en buena medida tienen que ver con tareas propias del derecho penal que no interesan al derecho sancionatorio administrativo, que no busca etiquetar al infractor de forma tan estricta, de conformidad con la gravedad relativa de su comportamiento.

Por último, el principio de culpabilidad, que también se oponía a la aplicación indiscriminada de un concepto unitario y extensivo de autor en el derecho penal, parece tener alcances bastante más acotados en el derecho sancionatorio administrativo, sin que la diferencia entre dolo y culpa tenga que reflejarse en la magnitud de la sanción. ${ }^{89}$

Ahora bien, volviendo a la cuestión del nivel de precisión y transitividad de las normas que facultan a la administración para imponer sanciones a quienes incurran en infracciones administrativas, una revisión de diversos sectores de la legislación nacional aporta una perspectiva diferenciada, que sugiere posibilidades también diversas de la Administración para dar alcance a comportamientos de quienes no ejecutan directamente la conducta infractora, trátese de los intervinientes de primer orden o de intervinientes secundarios.

\section{b.1. Legislación sancionatoria moderna}

Así, en primer lugar, en no pocas áreas del derecho sancionatorio administrativo será posible advertir tendencias legislativas similares, y aun con mayor acento, a las señaladas por Rotsch respecto de la legislación penal moderna: la abstracción de los intereses protegidos o la anticipación de las sanciones a conductas (tentativa, actos preparatorios) más alejadas de la efectiva lesión del bien jurídico. Así, el medio ambiente, la salud pública, la integridad y transparencia del mercado de valores, la seguridad y fluidez en el tráfico vial, ya son intereses bien abstractos, protegidos a través de la sanción de comportamientos que, con frecuencia, están muy adelantados en relación con la

teleológicamente comprendidas en el programa sancionatorio promovido por el legislador para el logro de los objetivos de política pública buscados, y siempre que aquel órgano implemente previamente mecanismos, desarrollando reglas, que hagan previsible al particular esa extensión. Supra, 1.

88 Supra, a.3, en este apartado 2.2.

89 Que incluso, en no pocos casos, en la jurisprudencia administrativa y judicial chilenas, se impone por la mera infracción de deberes objetivos fijados por la ley. Este juicio lo debo al documentado análisis de Pablo Soto, tesista doctoral del programa de Doctorado en Derecho de la Universidad Diego Portales, quien destina al asunto dos capítulos de su tesis doctoral (aun en progreso y, por ello, todavía inédita, pero que gracias a su autor tuve la oportunidad de consultar). 
lesión de aquellos intereses. Ello se puede traducir en formulaciones legales bastante intransitivas, como la que confiere potestad a la Superintendencia del Medioambiente para sancionar "[e]l incumplimiento de las Normas de Emisión, cuando corresponda" (art. 35, letra h, de la Ley $N^{\circ}$ 20.417). Ese tipo de formulación, es evidente, no define círculo alguno de intervinientes susceptibles de ser sancionados; además, la cuestión de hacer previsible qué formas de emisión contrarias a las normas son sancionables se traspasa a las reglas que debe establecer la autoridad ambiental, a través de los mecanismos de implementación y desarrollo de sus potestades..$^{90}$

Este tipo de legislación permitirá sancionar, por igual, tanto a los intervinientes de primer orden como a intervinientes con un rol secundario, sin entrar en colisión con la exigencia de legalidad de la infracción.

\section{b.2. Legislación sancionatoria con técnica regulatoria transitiva}

Sin embargo, la ley puede contemplar descripciones más precisas de la conducta, también desde el punto de vista de la identificación de los intervinientes. Por ejemplo, el artículo 109 de la Ley del Tránsito (D.F.L. No 1, del 29 de octubre de 2009) dispone que "[n] inguna persona podrá conducir un vehículo cuando se encuentre en condiciones físicas o psíquicas deficientes". Esta prohibición, si se la examina bien, está establecida por una norma transitiva, que deja claramente delimitado el ámbito de conductas susceptibles de sanción y, con ello, el círculo de intervinientes sancionables, pues ellos deben estar realizando una actividad muy específica, conducir un vehículo, de modo que la previsibilidad de la sanción se pone en tela de juicio con una aplicación de la misma más allá de los márgenes señalados por el tenor de la norma; en efecto, quien solicita a una persona que está en condiciones físicas deficientes que conduzca un vehículo para trasladarlo a otro lugar, no está conduciendo él mismo. Tampoco conduce quien, accediendo a la petición del que está en condiciones físicas deficientes, le presta el vehículo en el que aquél ha de conducir. Sancionar en cualquiera de esos casos a quien no conduce el vehículo afecta la necesaria previsibilidad de la sanción administrativa. Por otra parte, incluso si la sanción se hiciera previsible para el particular, por ejemplo, a través de la dictación de disposiciones reglamentarias, habría que elevar objeciones de legalidad desde la perspectiva democrática de separación de poderes, pues no parece posible sostener en este caso que la ley, a través de la fijación de un estándar general, haya entregado a la Administración, en aras de la consecución de los objetivos

90 Cuestión sobre la cual se volverá, infra, b.3., en este mismo apartado 2.2. 
de política pública buscados, la potestad de desarrollar reglas que definan los contornos y el alcance de la prohibición..$^{91-92}$

Estas dificultades planteadas por la legislación que emplea una técnica más transitiva afectarán las posibilidades de sancionar tanto a algunos de los intervinientes de primer orden (como el caso de quien ordena a su dependiente conducir en condiciones físicas deficientes), como a intervinientes secundarios (como el caso de quien sólo facilita el automóvil al conductor defectuoso, a petición de éste).

\section{b.3. Infracciones fundadas en deberes positivos especiales}

Pero los obstáculos más frecuentes a la afirmación de un concepto unitario de autor en el derecho sancionatorio administrativo, o de ampliaciones del ámbito de la autoría en la línea de lo sugerido por Rotsch, vendrán seguramente planteadas por la circunstancia, del todo habitual, de que la norma especifique una calidad especial de la que debe ser portador aquel a quien se dirige un deber especial, en términos de un mandato o una prohibición, especificando también, por esa vía, la conducta, lo que sería una forma sui generis de transitividad. Se trata de un tipo peculiar de norma, respecto de la cual la singularización de la acción principal pasa por la identificación del sujeto que, siendo portador de la calidad relevante, es destinatario del deber especial. Quienes no son destinatarios de ese deber, aunque realicen materialmente la conducta prohibida, sólo pueden contribuir a su infracción de modo auxiliar, a través de su influjo en el infractor que ejecuta la acción principal.

El problema se puede ilustrar con el siguiente caso imaginario. Un empresario minero dedicado a la explotación del cobre, conociendo el estudio de impacto ambiental que da cuenta de que una faena proyectada producirá emisiones que superarán la norma, con el propósito de eludir una posible responsabilidad

\footnotetext{
91 Ni siquiera a través del recurso al tópico de la responsabilidad del propietario del vehículo, si se tiene en cuenta que el propio legislador ha fijado los límites de una tal responsabilidad, abarcando sólo a "las infracciones que se deriven del mal estado y condiciones del vehículo" (art. 170 de la Ley del Tránsito), no así a las que se deriven de las condiciones deficientes del conductor. Se trata de una definición legislativa que fija una directriz clara, que no parece disponible por la Administración, sin afectar el principio de legalidad.

92 Y, en mi opinión, no se llegaría a resultados distintos si esas conductas (de inducción o complicidad) se desarrollan respecto de quien está en condiciones psíquicas (no físicas) deficientes para conducir. Incluso en caso de que se le induzca a conducir en ese estado, la posibilidad de recurrir a la noción de autoría mediata -aun prescindiendo de la exigencia de una cláusula general, como causa de extensión de la sanción, exigencia que en el derecho sancionatorio administrativo podría tener menos justificación que en el derecho penal- es del todo dudosa, tal como ocurre respecto de figuras similares contenidas en el derecho penal (conducción en estado de ebriedad), por tratarse de una infracción de propia mano. Así lo entiende la doctrina mayoritaria en Alemania; KINDHÄUSER (2013), § 323, nm 22.
} 
sancionatoria administrativa externaliza la explotación de la faena convenciendo a pequeños mineros, ignorantes de su carácter contaminante, de que sean ellos quienes la exploten y le vendan toda la producción.

El artículo 35, letra h), de la Ley Orgánica de la Superintendencia del Medio Ambiente (creada por el artículo segundo de la Ley $N^{\circ}$ 20.417), entrega a la Superintendencia potestad para sancionar "[e]l incumplimiento de las Normas de Emisión, cuando corresponda", con las más severas sanciones que contempla la ley cuando, de conformidad con el artículo 36, № 1, letra a), de la misma ley, las infracciones "[h]ayan causado daño ambiental, no susceptible de reparación".

La definición de esa infracción se encuentra complementada y desarrollada, entre otros instrumentos, por el D.S. № 28 sobre norma de emisión para fundiciones de cobre, ${ }^{93}$ cuyo artículo $5^{\circ}$ fija a las "otras fuentes industriales emisoras de arsénico existentes" (distintas de las grandes fundiciones de cobre reguladas en los artículos anteriores), una emisión máxima de $\mathrm{SO}_{2}$ (dióxido de azufre) de 400 ppm (partes por millón en volumen), a verificar como concentración promedio horaria, durante cada hora de operación de la planta de ácido.

A la hora de preguntarse quién está vinculado por esa prohibición, la primera señal la entrega la ley, que permite a la Superintendencia, en el ya citado artículo 35, letra h, sancionar el incumplimiento de las normas, aclarando luego que las sanciones más severas se aplicarán a las infracciones de la misma (que hayan causado el tipo de daño ahí especificado). Esas referencias se entienden hechas, entonces, a quien debiendo haber cumplido con las normas de emisión, dejó de hacerlo, las infringió. Y, de acuerdo con el lenguaje del D.S. № 28, las obligaciones y límites impuestos por las normas de emisión se refieren, conforme a su artículo 16, a los "titulares de fuentes emisoras", la misma expresión empleada por los artículos $3^{\circ}$, letra m), y 35, letra h), de la Ley Orgánica de la Superintendencia del Medio Ambiente.

Ahora bien, por titular de una fuente emisora es lógico entender a la persona natural o jurídica que tiene derechos de explotación sobre la fuente y, con ello, la facultad de decidir las condiciones en que se desarrollará la actividad que genera emisiones.

La cuestión que surge, entonces, en el caso propuesto, es la de si puede responder como autor mediato quien, habiéndose servido, para perpetrar el hecho, de un instrumento (humano) que contaba con la calidad requerida por la norma (ser titular de la fuente de emisión) para el destinatario de la prohibición (sujeto denominado, en derecho penal, intraneus), no cuenta sin embargo él mismo -el supuesto autor mediato- con dicha calidad (es decir, es un extraneus). En

93 Decreto Supremo № 28, del 30 de julio de 2013 (D.O. 12 de diciembre de 2013), del Ministerio del Medio Ambiente, que establece la norma de emisión para fundiciones de cobre y fuentes emisoras de arsénico. 
el derecho penal, que denomina delitos especiales propios a los que suponen en el autor una calidad especial, se rechaza la posibilidad de reconocer como autor (incluso, como autor mediato) a quien no cuenta con esa calidad especial. Con todo, la ya referida teoría de los delitos de infracción de deber, como ya se señaló, ${ }^{94}$ sí permite castigarlos como partícipes (inductores o cómplices según el caso). Pero, en este caso, incluso según esta teoría, la sanción al extraneus como partícipe (inductor, en este caso) no sería practicable, como ya se ha señalado, si no se cuenta con una cláusula de incriminación expresa. Así, en el ejemplo propuesto no podría sancionarse al empresario que maliciosamente maquinó este modelo de negocio contaminante, por no ser destinatario de la prohibición (al no ser titular de la fuente emisora).

Hay razones materiales para rechazar este resultado en el derecho sancionatorio administrativo, en la medida que en esta rama del derecho no interesa tanto (o no en absoluto) un especial desvalor de acción que surgiría de la infracción del deber por parte del sujeto cualificado, cuanto la prevención de daños (desvalor de resultado) producidos en el contexto de ciertas actividades que son especificadas a partir de la presencia de esos sujetos cualificados. ${ }^{95}$ Pero en la medida que la norma parece dirigirles deberes en exclusiva a ellos, surgen problemas para sancionar a los que parecen quedar fuera de su alcance. ${ }^{96}$

Sin embargo, como contrapartida, la proliferación, en la legislación administrativa, de infracciones fundadas en deberes positivos especiales, abre la posibilidad-siempre que se acoja la teoría de los delitos de infracción de deber en esta rama del derecho- de sancionar a los especialmente obligados, a título de autor, aun si no incurren directamente en la conducta, en la medida de que hayan intervenido en la infracción de cualquier forma (aun mediante una omisión), incumpliendo su deber especial.

Como saldo, y bajo el supuesto de que se acoja la referida teoría, esta proliferación de infracciones fundadas en deberes positivos especiales, en general mejora la posibilidad de sancionar a los intervinientes de primer orden, que normalmente contarán con las calidades especiales que los convierten en destinatarios del deber respectivo. Los casos en que la falta de esa calidad en los intervinientes de primer orden impida alcanzarlos con la sanción, como el del ejemplo del empresario minero que elude asumir como titular de la fuente de emisión, serán más bien de rara ocurrencia. Esta conclusión, en todo caso, deja

\footnotetext{
94 Supra, a. en este apartado 2.2.

95 Así Bloy (1985), pp. 156-159.

96 Problemas que, como destaca el propio Bloy, en el derecho alemán se resuelven con una norma que, consagrando un sistema unitario de autor, comunica las características personales presentes en unos intervinientes a los extraneus. Infra, apartado 3.1., y las correspondientes notas al pie.
} 
fuera la hipótesis especial en que la calidad especial esté referida a la persona jurídica y la persona natural que actúa a nombre de ella carece de la misma, pero es materialmente responsable de la infracción, hipótesis que se examina en el apartado siguiente. ${ }^{97}$

\section{b.4. Legislación sancionatoria con técnica regulatoria menos transitiva}

Hecho este análisis, ahora podemos volver al examen -pendiente- de la legislación intransitiva que, como se dijo, confiriendo a la autoridad administrativa potestades sancionatorias con directrices más laxas, traspasa con ello a la Administración la exigencia de establecer reglas, a través de sus dispositivos de implementación de la ley, con las que se provea al particular de previsibilidad de las sanciones.

El problema se plantea, por ejemplo, con las reglas administrativas que desarrollan, respecto de determinadas infracciones, la norma legal del artículo 204, inc. $4^{\circ}$, de la Ley del Tránsito, que sanciona con multa "[a]l que transporte cargas peligrosas sin ajustarse a las normas reglamentarias que rigen la actividad", planteando la duda de si se refiere al conductor o si al empresario de transporte. El D.S. $N^{\circ} 298$, sobre Transporte de Cargas Peligrosas, ${ }^{98}$ refiere, por ejemplo, una de esas reglas al conductor, cuando en el artículo 23 establece que "[s] prohíbe al conductor y auxiliares abrir un bulto que contenga materiales peligrosos". Por razones similares a las que lo impedirían si se tratase de una prohibición legal de tal tenor, al empresario que induzca al conductor a abrir el referido bulto no se le puede sancionar con base en el artículo 23 del D.S. N ${ }^{\circ} 298$; ni existe una norma distinta que extienda la sanción a inductores o cómplices. ${ }^{99}$ Es más, aunque el resultado es algo absurdo, en rigor sería problemático sancionar al transportista que, habiendo solicitado al conductor que le indique dónde se encuentra el bulto, decide él mismo directamente abrirlo, pues aquél no es conductor o auxiliar. ${ }^{100}$

97 Infra, apartado 2.3.

98 D.S. N N 298, de 25 de noviembre de 1994, sobre Transporte de Cargas Peligrosas por calles y caminos (D.O. 11/02/1995).

99 Un caso algo más obscuro, es el del artículo 17, conforme a la cual "[l]os vehículos que transporten sustancias peligrosas deberán evitar el uso de vías en áreas densamente pobladas y no podrán circular por túneles cuya longitud sea superior a 500 m, cuando éstos tengan una vía alternativa segura". Si la prohibición se entiende referida, como parece, al conductor, no parece posible sancionar como cómplice al empresario que facilite al conductor el camión, sabiendo que éste usará un túnel de tales características. Lo discutible es si la prohibición dirigida a "los vehículos", no se refiere también -algo oblicuamente- al empresario.

$100 \mathrm{Y}$ en tal caso, tampoco parece posible sancionar al conductor recurriendo a la tesis de que él sería autor de un ilícito de infracción de deber pues, aunque se trata aquí de un ilícito especial que 
En cambio, y siempre que se recurra a la solución acogida en el derecho penal por la teoría de los delitos de infracción de deber, no sería problemático sancionar al transportista, como autor de la infracción del artículo 31 del mismo D.S. № 298, conforme al cual "[e]l transportista no deberá recibir carga de sustancias peligrosas si el expedidor no le hace entrega de las instrucciones escritas a que se refiere la letra b) del artículo anterior", aun si no fue aquél, sino el conductor, quien recibió materialmente la carga, por instrucciones del transportista. En efecto, de conformidad con esta teoría, como ya se indicó, sería autor de un ilícito de infracción de deber quien siendo destinatario del deber especial cuya infracción es condición de realización del respectivo tipo -en este caso, el transportista- interviene en él de cualquier forma (induciendo a otro a ejecutarla o incluso cooperando con este otro) infringiendo conscientemente su deber, sin necesidad, entonces, de una cláusula de extensión de la sanción a los partícipes. ${ }^{101}$ Y quien no es destinatario de ese deber especial -en este caso, el conductor- no puede ser autor de tal ilícito, por más que haya ejecutado materialmente la acción; sólo podría ser calificado de cómplice, ${ }^{102}$ si existiese una cláusula de la sanción que alcance a estos partícipes, cláusula que justamente no existe en el derecho sancionatorio administrativo. ${ }^{103}$

Para ofrecer un ejemplo de otro sector, piénsese en las siguientes dos variantes del caso de la infracción de las normas de emisión establecidas para una faena de explotación de cobre: (1) un asesor jurídico de la empresa recomienda al representante de la persona jurídica titular de la fuente continuar con la actividad

requiere una calidad determinada en el autor, es muy dudoso que esa calidad se refiera a un deber (positivo) especial, siendo éste un ejemplo semejante al de los delitos especiales propios que no son, sin embargo, de infracción de deber; al respecto, JAKOBS (1995) apartado 23 nm 24-25, si bien empleando las denominaciones "delitos especiales en sentido amplio" (para los delitos especiales que no son de infracción de deber) y "delitos especiales en sentido estricto" (para los que sí son de infracción de deber).

101 Roxin (2003) t. II § $25 \mathrm{~nm}$ 268. Sin embargo, si se reconoce en esta infracción la estructura de una "infracción de deber referida al resultado", así Roxin (2003) t. II § 25 nm 271-272, se trataría de un caso de autoría mediata, para la cual, ya se señaló, es necesaria, según alguna doctrina -que, tratándose de responsabilidad penal, tiendo a compartir- la existencia de una cláusula de extensión de la punibilidad. Para CURY (2005), pp. 619-620, siempre se trataría de autoría mediata, salvo cuando el obligado se aprovecha de un error de tipo del instrumento. En todo caso, aun entre los partidarios de la teoría de los delitos de infracción de deber, cabe destacar la postura de Silva Sánchez, quien Ilama la atención acerca de que para determinados delitos de infracción de deber la autoría no se satisfacen por la mera infracción del deber sino que se requiere, de parte del autor, "ciertos actos concretos de organización; OSSANDÓN (2007), pp. 166, 182, citando a ese autor a propósito del caso de los delitos tributarios, y, sucintamente, Couso (2012), p. 105. Tal no parece ser el caso, con todo, de la infracción administrativa examinada en el texto principal.

102 Roxin (2003), § $25 \mathrm{~nm} 271-272$.

103 Con todo, infra, en el apartado 2.3., la discusión sobre si en este caso el conductor puede ser sancionado por actuar en lugar de otro -del transportista-. 
que genera emisiones, aun a pesar de exceder la norma, pues las ganancias serán superiores al monto probable de la multa; y (2), un experto, contratado como consultor, que asegura que la emisión se ajusta a la norma, en circunstancias que él sabe que no lo hace. En el primer caso, el representante de la empresa decide dar curso a la explotación de la faena, siguiendo el consejo del asesor jurídico; en el segundo caso, haciendo fe de lo que dice el experto, por error (sobre el carácter contaminante de la faena), decide explorarla. ¿Pueden entenderse vinculados por la norma administrativa que fija el máximo de emisiones permitidas, y puede considerarse infractores de la misma, respectivamente, al asesor jurídico y al consultor experto?

Me parece que las mismas razones que impedirían considerarlos a ellos como infractores, si fuese la ley -mediante una legislación transitiva- la que definiese la norma y los deberes, también impiden hacerlo cuando es la Administración la que fija tales normas y deberes, en el marco de la implementación de una legislación intransitiva (el artículo 35, letra h de la Ley Orgánica de la Superintendencia del Medio Ambiente) y en ejercicio de su potestad reglamentaria. El asesor jurídico y el consultor experto sólo pueden considerarse inductores, no sancionables en la medida que no exista una cláusula expresa que extienda a ellos la responsabilidad. ${ }^{104}$

Por cierto, la gran diferencia entre esta última situación y la de una legislación transitiva radica en que la Administración podría, en el marco de una legislación intransitiva, hacer previsible la sanción para asesores jurídicos o consultores si, a partir de aquel estándar legal más bien laxo (no se deben generar emisiones que causen un daño irreparable al medio ambiente), se encarga de producir una regla precisa para los potenciales infractores; por ejemplo: "será sancionable [con determinada sanción] quien, como titular de una fuente, generare emisiones de $\mathrm{SO}_{2}$ superiores a [... un determinado volumen], así como quien determinare a éste a generarlas".

Pero una decisión de ese tipo, aunque previsible una vez que se fija y comunica la regla, Ilamaría la atención por lo ad hoc de su fundamento. ¿Por qué hacer responsables a asesores jurídicos y consultores expertos sólo en materia de ciertas emisiones contrarias a la norma ambiental, y no para cualquier otra actividad que afecte al medio ambiente? ¿Y por qué no extender la responsabilidad del asesor jurídico y del consultor experto a otras áreas de la actividad privada sometida a la potestad sancionatoria de la Administración? La falta de una respuesta satisfactoria, bastante probable si la autoridad competente para

104 Desde este punto de vista, teniendo la infracción administrativa una estructura similar a la de un delito de infracción de deber, incluso el operario que materialmente efectúa el vertido no sería autor de la acción principal, directamente sometida a la norma de prohibición, sino un mero cómplice, cuya responsabilidad, de nuevo, no podría afirmarse sin una cláusula expresa que extienda a él la sanción. 
fijar la regla únicamente estaba preocupada de un sector, podría ser indicio de que la decisión, si bien no es imprevisible, puede ser criticada por arbitraria. Razón de más para preferir que la decisión de ampliar el círculo de destinatarios de un deber reforzado por medio de una sanción administrativa, más allá de su infractor principal, alcanzando así a quien sólo de un modo auxiliar ha incidido en tal infracción, responda a parámetros legales más o menos generales.

De nuevo, en conclusión, el círculo de destinatarios de una prohibición o prescripción bajo amenaza de sanción administrativa, parece que queda circunscrito por el concepto de autor de la respectiva infracción, entendido como aquel que está en situación de ejecutar la acción principal que la norma se propone impedir. Extender a otros la sanción es posible, pero exige una actividad regulatoria, legislativa o administrativa, idealmente, en este último caso, en base a criterios generales y no ad hoc.

\subsection{El actuar en lugar de otro y la responsabilidad del superior en el derecho sancionatorio administrativo}

\section{a. El actuar en lugar de otro}

Otro problema relevante relacionado con la autoría en las infracciones administrativas es el que en el derecho penal se trata bajo el tópico de la responsabilidad por el actuar en lugar de otro, ${ }^{105} \mathrm{o}$ de la responsabilidad del representante. ${ }^{106}$

El problema se plantea en el derecho penal como una posible laguna de punibilidad en los casos de delitos especiales propios -los que requieren una calidad especial en el infractor, sin la cual la conducta no es en absoluto sancionable, ni siquiera con menor pena- cuya conducta sea perpetrada por el representante no cualificado (es decir, que no cuenta con aquella calidad especial) actuando por un representado cualificado.

El problema también se puede plantear en el derecho sancionatorio administrativo. Para apreciar la posible laguna de sancionabilidad, piénsese en infracciones que no son susceptibles de sanción cuando se actúa en beneficio de otro. Por ejemplo, puede tratarse de la infracción a que se refiere el artículo 200 de la Ley de Mercado de Valores, que se verifica cuando un accionista que ha tomado el control de una sociedad, dentro de los doce meses siguientes adquiere acciones de la misma por un monto igual o superior al $3 \%$, sin efectuar una oferta pública de acciones. Pues bien, si el accionista que logra el control

\footnotetext{
105 Así, por ej., la denominación usada por el CP alemán, en el § 14 StGB ("Handeln für einen Anderen").

106 Así, el Proyecto Alternativo de CP alemán de 1966 (2 $2^{a}$ versión de 1969); y también Roxin (2003), $\S 27 \mathrm{~nm} 84$.
} 
de la sociedad es una persona jurídica, y la adquisición fue efectuada por su gerente general, entonces la acusada laguna legal consistiría en que al gerente general no se le podría sancionar, pese a haber efectuado la compra prohibida, pues él no es accionista. Con todo, el caso de la Ley de Mercado de Valores es uno peculiar, pues la propia ley ha contemplado una regla expresa de responsabilidad del representante, en el artículo 55, inciso $2^{\circ} .{ }^{107-108}$

¿Pero qué sucede cuándo la ley no ha establecido una causal de ese tipo?

Para seguir con un ejemplo ya tratado en este trabajo, el caso podría darse si el gerente general de una sociedad que es titular de una determinada explotación minera $-y$, con ello, titular de la fuente de emisión- dispone efectuar emisiones de arsénico que exceden la norma, lo que, para el titular de la fuente supondría una contravención del artículo 55, letra h), de la Ley Orgánica de la Superintendencia del Medio Ambiente, en relación con el artículo $5^{\circ}$, letra a), del D.S. № 28, de 2013, del Ministerio del Medio Ambiente. El gerente general, sin embargo, no es el titular de la fuente, sino su representante. Y la Ley Orgánica de la Superintendencia del Medio Ambiente no contiene una norma sobre el actuar en lugar de otro (como la que sí contempla, en cambio, el artículo 55, inc. $2^{\circ}$, de la Ley de Mercado de Valores) ¿Se le puede sancionar? Al parecer, no hay obstáculos legales para sancionar a la sociedad que se constituye como titular del proyecto de explotación, ${ }^{109}$ que funge como titular de la fuente emisora. ${ }^{110}$ Pero, ¿puede sancionarse también al gerente general que ordenó la emisión?

Una cuestión se plantearía, por ejemplo, si en el Caso Blackout se buscase sancionar al gerente o a los miembros del directorio por la desconexión de la central Rapel, ${ }^{111}$ considerando que ninguno de ellos es una "empresa

107 Que reza, textualmente: “[p]or las personas jurídicas responderán, además, civil, administrativa y penalmente sus administradores o representantes legales a menos que constare su falta de participación o su oposición al hecho constitutivo de infracción." La misma regla se encuentra en el artículo 133, inc. $2^{\circ}$, de la Ley N N 18.046, de Sociedades Anónimas (D.O. 22/10/1981).

108 Agradezco a Fernando Londoño llamar mi atención sobre este caso de regulación expresa de la responsabilidad del que actúa en lugar de otro.

109 La Ley de Bases Generales del Medio Ambiente, № 19.300, emplea, de hecho, esta expresión, "titular del proyecto o actividad", por ejemplo, en los artículos $8^{\circ}, 9^{\circ}$ y 11 , para regular la obligación de efectuar una evaluación de impacto ambiental.

110 Con ello, como se puede apreciar, y a diferencia de lo que ocurre en el derecho penal chileno, en nuestro derecho sancionatorio administrativo el problema no es estrictamente de una laguna de punibilidad absoluta, pues puede sancionarse directamente a la persona jurídica, sino de una laguna de punibilidad relativa, si se considera que la conducta del gerente general, en estos casos, es materialmente merecedora de sanción.

111 Por ahora se pasa por alto que esta hipótesis plantea otra cuestión adicional: la responsabilidad del superior por el comportamiento de su subalterno. Infra, ben este apartado 2.3. 
concesionaria", ni reúne las calidades señaladas en el artículo 12 del D.S. N ${ }^{\circ}$ 291 de $2007 .{ }^{112}$

En el derecho penal, para sancionar a los representantes en casos como los propuestos, hay una amplia tendencia a reconocer la necesidad de una cláusula especial para el que actúa a nombre de otro, cláusula que de hecho ha sido acogida en varios códigos penales. ${ }^{113}$

En el derecho sancionatorio administrativo, la laguna podría ser aún más extensa. Pues, en el derecho penal el problema no se plantearía cuando el sujeto no cualificado puede ser considerado inductor, cómplice o incluso coautor del sujeto que cuenta con la cualificación especial. ${ }^{114}$ En cambio, y más allá de las dificultades que puede entrañar la afirmación de algunas de esas formas de cointervención - ¿la coautoría?- con una persona jurídica, en el derecho sancionatorio administrativo ellas no son susceptibles de sanción, como ya se señaló, a falta de cláusulas legales expresas.

Con todo, la afirmación de una laguna de punibilidad en algunos de estos casos es discutible, ya en el derecho penal. En efecto, en los casos de actuación del órgano a nombre de la persona jurídica, se ha postulado que la norma de conducta del delito especial debería entenderse referida directamente a dicho órgano o representante con capacidad de acción; o bien, que su responsabilidad podría derivarse de la identificación de un deber de garante recaído en el mismo órgano o representante, como fundamento de su propia competencia por la evitación de la conducta. ${ }^{115}$

\footnotetext{
112 Referido a los "propietarios, arrendatarios, usufructuarios o quienes exploten, a cualquier título, centrales generadoras, líneas de transporte, instalaciones de distribución y demás instalaciones señaladas en el Artículo $2^{\circ}$ del presente reglamento, que se interconecten al sistema".

113 Así, por ejemplo, en el derecho español, ya antes de la introducción de la regla, MiR PUIG (1996), p. 177 y n. 65, refiriéndose a un planteamiento hecho por Muñoz Conde en el año 1977); y en el derecho alemán, las referencias en VAN WeEzel (2013), pp. 287 y ss., y passim. En relación con el derecho chileno, si bien se han introducido algunas reglas en la Parte Especial (en la Ley de Quiebras, arts. 232 y 233), así como en relación con los delitos tributarios (art. 99 del Código Tributario), y en la propia Ley de Mercado de Valores (el artículo 55, inc. $2^{\circ}$, es aplicable también a la responsabilidad penal), en otra materias que plantean el mismo problema no se contemplan reglas similares; así, por ejemplo, en el caso del fraude del deudor prendario, del art. 39 de la Ley de Prenda sin Desplazamiento, así como en el de la sustracción por parte del ejecutado de los bienes embargados, del art. 444 del CPC; en tal sentido, Van Weezel (2013), pp. 284-285. Sintomático de la extendida opinión a favor de la necesidad de una cláusula expresa es su incorporación en los dos últimos anteproyectos de Código Penal preparados a instancias del Ejecutivo, los años 2013 y 2015.
}

114 Así, sosteniendo que la laguna de punibilidad no se presenta cuando operan las reglas de intervención delictiva, VAN WeEZEL (2013), p. 304.

115 Van WeEZel (2013), pp. 307 y ss., refiriéndose al análisis de la estructura de las normas penales hecho por Nagler. 
Pero aun si ello es sostenible, la laguna sí se produciría, en el derecho penal, en los casos de representación convencional contingente en que falta una relación de cointervención delictiva. ${ }^{116}$ En esos casos, a falta de una regla legal en la Parte Especial, o en la Parte General, la resolución de la laguna de punibilidad por una vía puramente interpretativa, como la que recurre sin más a la afirmación de un deber de garante en el representante, podría infringir el principio de reserva de ley en materia penal, ${ }^{117}$ tal como se sostenía en España hasta antes de la introducción de la regla del art. 31 del CP español. ${ }^{118}$

¿Es sostenible ello en el derecho sancionatorio administrativo?

El caso parece presentarse, por ejemplo, si el dueño de las faenas mineras que efectúa emisiones es una persona natural que, luego de un tiempo de dirigir personalmente la explotación de la faena, cumpliendo escrupulosamente con las normas medioambientales, decide mandatar a otra persona natural para la administración de la misma, y es ésta la que efectúa, por ejemplo, emisiones que superan la norma. ¿Cabe sancionar al dueño de las faenas por la infracción del artículo 53, letra h) de la Ley Orgánica de la Superintendencia del Medio Ambiente? ¿Cabe hacerlo respecto del mandatario? El primero no efectuó las emisiones en exceso, ni directamente, ni ordenando a alguien o tolerando de otro que lo hiciera. Sencillamente mandató a otra persona para administrar la faena. Y esta otra persona, el mandatario, aparentemente no es "titular" de la fuente emisora. La Ley de Bases Generales del medio Ambiente parece entender como titular de las obligaciones medioambientales al titular del proyecto o actividad que efectuó o debió efectuar -si es el caso- la declaración o estudio de impacto ambiental (art. $9^{\circ}$ ). Si se trataba de una faena que fue puesta en funcionamiento por el dueño, él parece seguir siendo el titular de la fuente. Pero, como se señaló, él no ha efectuado emisiones que infringen la norma, sino su mandatario, quien justamente no aparece como titular de la fuente. Es obvio que el absurdo resultado de que no se sancione a ninguno de los dos debe ser evitado. Pero ¿qué norma autoriza a evitarlo, y de qué modo?

Otro caso puede darse en relación con una de las ya referidas reglas administrativas sobre transporte de sustancias peligrosas. El artículo 31 del D.S.

\footnotetext{
116 Como la hipótesis que regulaba el ya derogado art. 233 de la Ley de Quiebras, referido a los "factores o representantes del fallido que sea persona natural" que en representación de éste realicen las conductas típicas de quiebra culpable o fraudulenta; VAN WEezel (2013), pp. 309, 305. Esa hipótesis podría entenderse actualmente cubierta por el artículo 463 quater del Código Penal (que también abarca, por cierto, los casos menos problemáticos en que el autor es representante legal de un deudor persona jurídica).

117 Así, Van Weezel (2013), pp. 303, 307-308.

118 Cfr. Mir PUIG (1996), p. 177.
} 
№ 298, sobre Transporte de Cargas Peligrosas, ${ }^{119}$ dispone que "[e]I transportista no deberá recibir carga de sustancias peligrosas si el expedidor no le hace entrega de las instrucciones escritas a que se refiere la letra b) del artículo anterior". Pues bien, si sin conocimiento del transportista es el conductor, y no aquél, el que recibe la carga (sin haber recibido las instrucciones escritas del expedidor), no cabe sancionar al transportista, pues no ha incurrido personalmente en la prohibición. ${ }^{120} \mathrm{Y}$, al conductor, por su parte, ¿cabe sancionarlo, pese a que justamente no reviste la calidad de transportista? La falta de cláusula expresa vuelve problemática la sanción.

En otros sectores del derecho sancionatorio administrativo, aun sin cláusula de responsabilidad por el actuar en lugar de otro, el legislador se ha preocupado de mencionar -junto al dueño, propietario o titular a cada infracción- al "encargado" u otro sujeto materialmente vinculado a la infracción, ${ }^{121}$ resolviendo el problema, pero ofreciendo también un argumento en contra del expediente de extender, en la aplicación del derecho, otras infracciones administrativas a quienes actúan en lugar del especialmente obligado.

En conclusión, aunque buena parte de los casos relevantes -sobre todos los referidos al representante de las personas jurídicas- pueden ser resueltos sin necesidad de una cláusula sobre el actuar en lugar de otro, la sanción puede volverse problemática en algunos otros, sobre todo teniendo en cuenta que la ley sólo de modo fragmentario se ha preocupado de resolver el problema de modo expreso.

\section{b. La responsabilidad del superior}

Por último, para examinar el problema de la responsabilidad del superior puede introducirse una pequeña variante en uno de los casos ya examinados a propósito del actuar en lugar de otro.

El vertido que se tradujo en una emisión superior a la norma puede haber sido efectuado por un jefe de operaciones, actuando a nombre de la empresa, y habiéndose visto su conducta favorecida por la falta de supervisión adecuada del gerente.

119 D.S. NN 298, de 25 de noviembre de 1994, sobre Transporte de Cargas Peligrosas por calles y caminos (D.O. 11/02/1995).

120 Nótese que esta hipótesis difiere de la planteada supra, b.4. en el apartado 2.2., pues ahora no se supone que el transportista haya instruido al conductor a realizar esta conducta.

121 Así, por ejemplo, el artículo $7^{\circ}$ de la Ley del Tránsito, D.F.L. № 1, de 27 de diciembre de 2007 (D.O. 29/10/2009), "prohíbe al propietario o encargado de un vehículo facilitarlo a una persona que no posea licencia para conducirlo". Por su parte, el artículo 101, inc. 11, del Código Sanitario sanciona a "[e]l propietario, el director técnico y el auxiliar de la farmacia en que se expenda un medicamento diferente del indicado en la receta, contraviniendo lo dispuesto en el presente artículo". 
¿Es posible sancionar al gerente que, a diferencia de las hipótesis antes examinadas, no ha actuado en lugar de otro, sino que simplemente no ha ejercido de forma adecuada su papel de supervisión del trabajo de quien efectivamente actuó, el jefe de operaciones?

El problema también se plantea en la variante del Caso Blackout en la que a la Administración interesa sancionar al gerente o a los miembros del directorio. Pues, aun resuelta la cuestión de la responsabilidad del que actúa en lugar de otro, que permite extender a los representantes la cualidad especial requerida por la infracción (ser una empresa eléctrica concesionaria), todavía es necesario extenderles la conducta consistente en la desconexión del servicio, afirmando su responsabilidad en calidad de superiores del funcionario que materialmente incurrió en ella.

En estos casos, con todo, podría plantearse una responsabilidad del superior por omisión imprudente de impedir a los subordinados incurrir en una infracción administrativa. Después de todo, en el propio derecho penal se está planteando, si bien de forma muy incipiente, la posibilidad de hacer responder a los directivos de la empresa por ciertos delitos perpetrados por empleados de la misma, cuando los directivos imprudentemente dejaron de impedirlos, por falta de vigilancia o supervisión adecuada. ${ }^{122}$

Ello supone, con todo, desarrollar en sede sancionatoria administrativa una compleja dogmática sobre las funciones de garante y los presupuestos de equivalencia entre la responsabilidad por comisión omisiva y activa. Pero las complejidades son conceptuales, más que de principio. En general no serán atendibles reclamos de falta de previsibilidad. Y dado que en este caso se trata de los intervinientes de primer orden, ciertamente no vienen al caso objeciones formuladas a partir del principio de culpabilidad o de fair labelling.

\section{Perspectiva del derecho comparado: el modelo ofrecido por el derecho sancionatorio administrativo alemán}

Sin pretensiones de que, como ya ocurre en el derecho penal -seguramente, de modo excesivo- también ahora en el campo del derecho sancionatorio administrativo nuestra atención, a la hora de buscar soluciones, se dirija de modo tan unilateral al ordenamiento jurídico alemán, a lo menos una razón justifica una revisión sintética de su modelo: buena parte de los problemas que, para la eficacia del derecho sancionatorio administrativo, han surgido a causa de la importación a esta rama del derecho de los principios garantistas del derecho penal de inspiración alemana, en buena medida han sido resueltos por el

122 HeRnÁNDEZ (2013), passim, examinando los antecedentes jurisprudenciales y la doctrina alemana y de otros países europeos. 
propio derecho sancionatorio administrativo alemán. Ello no quiere decir, por cierto, que la forma en que fueron resueltos sea necesariamente satisfactoria en nuestro contexto.

\subsection{Concepto unitario de autor por expresa disposición legal}

En el campo de la autoría y la participación, en efecto, con el propósito de simplificar la aplicación del derecho, ${ }^{123}$ la Ley de Infracciones Administrativas $(O W i G)$ alemana de 1968 resolvió el problema que plantea la legalidad de la sanción a esos partícipes acogiendo expresamente un concepto unitario de autor, en el $\S 14.1$, primera frase, del siguiente tenor:

Si varios intervienen en una infracción administrativa, cada uno de ellos actúa de modo contrario al derecho administrativo. ${ }^{124}$

La regla ofrece un claro fundamento legal para la sanción a todo el que interviene (beteiligt) en la infracción, concepto que abarca tanto el comportamiento de los autores -incluidos el autor mediato y los coautores-como el de los partícipes -cómplices e inductores. ${ }^{125}$ El propósito de la disposición no es ampliar el círculo de los intervinientes susceptibles de sanción más allá del que es potencial destinatario de una pena en el derecho penal sino, asumiendo -y dando por supuesta la necesidad de ello- que todos los intervinientes han de ser sancionados, el propósito es simplificar la aplicación del derecho, exonerando a quien declarará la responsabilidad sancionatorio administrativa de la necesidad de fundamentar su decisión en base a la compleja dogmática de la autoría y participación. ${ }^{126}$ En efecto, autores, cómplices e inductores pueden ser sancionados sin distinción, sin perjuicio de que se deba atender, en sede de determinación de la cuantía de la sanción, a la diversa significación que en la práctica pueden tener los comportamientos de unos y otros. ${ }^{127}$ La única restricción inicial, afirmada por la jurisprudencia, es que sólo cabe sancionar a intervinientes dolosos en un hecho principal también doloso. ${ }^{128}$

Es decir, volviendo al Caso Cascadas, conforme a esa norma sería posible sancionar a Ponce Lerou por infringir la prohibición de efectuar operaciones con empresas relacionadas, contrarias al interés social; y ello, desde luego, sin

123 Como expresamente lo señala la Fundamentación de la Ley de Infracciones Administrativas alemana; RENGIER (2014) § $14 \mathrm{~nm} 2$.

124 En el original alemán: Beteiligen mehrere an einer Ordnungswidrigkeit, so handelt jeder von ihnen ordnungswidrig.

125 GÖHLeR (1990) § 14 nm 1; RenGier (2014) § 14 nm 2.

126 GÖHLER (1990), § $14 \mathrm{~nm} 2$.

127 GÖHLER (1990), § $14 \mathrm{~nm} 7$.

128 BGhst. 31, 309, cit. por RenGieR (2014) § 14 nm 5. 
necesidad de resolver si acaso es autor, inductor o cómplice de la sociedad infractora.

Más aún, el propio $\S 14.1$ de la $O W i G$ añade, en su frase segunda, que la extensión de responsabilidad a todos los intervinientes (autores, cómplices o encubridores) incluso procede en caso de tratarse de una de aquellas infracciones que suponen una calidad especial en el autor, como fundamento de la sanción, a condición de que cualquiera de ellos -aunque no se trate del autor-cuente con tal calidad. ${ }^{129}$ Ello permitiría sancionar a Larraín Vial por haber auxiliado a las sociedades cascadas a efectuar transacciones ficticias con valores. También permite sancionar a Endesa y a sus representantes por haber interrumpido el servicio eléctrico al dejar de mantener conectadas las instalaciones. ${ }^{130} \mathrm{Y}$ permitiría sancionar a la empresa minera titular de la fuente emisora que excede la norma de emisiones, a sus representantes y al asesor jurídico que indujo a éstos a emprender la explotación a sabiendas de la superación de la norma. Más aún, en la segunda variante propuesta para el caso de la empresa minera, en la que un consultor experto engañaba a los representantes de la empresa al señalarles que la explotación no será contaminante, el § 14 de la OWiG permitiría sancionar al consultor, ${ }^{131}$ siendo que, sin dicha disposición, su falta de la cualificación especial impediría considerarlo autor mediato, y la falta de un hecho principal típico -requerido por el principio de accesoriedad- ejecutado por los representantes (que actúan sin dolo) impediría sancionarlo como partícipe. La norma, en fin, también permitiría sancionar al transportista que, auxiliado por el conductor (que le indica dónde se encuentra el bulto), abre el bulto que contiene sustancias peligrosas, aun cuando aquél no tiene la calidad

129 Textualmente, en el original: Dies gilt auch dann, wenn besondere persönliche Merkmale ( $99 \mathrm{Abs}$. 1), welche die Möglichkeit der Ahndung begründen, nur bei einem Beteiligten vorliegen. Cfr., RENGIER (2014) $§ 14 \mathrm{~nm} 41$ y ss., criticando este "dudoso efecto de solidaridad" conforme al cual el extraneus sólo va a ser sancionado porque un intraneus ha tenido algún tipo de intervención.

130 En este caso, como ya se señaló, este efecto de la disposición, es cierto, podría alcanzarse de todos modos sin necesidad de ella, si se suscribe la teoría de los delitos de infracción de deber, pues en tal caso Endesa es autor por haber sus representantes infringido su deber aun cuando no hayan realizado el comportamiento exigido por el tipo.

131 Así, GöHLer (1990), § $14 \mathrm{~nm}$ 12. Sin referirse expresamente a la constelación, al mismo el resultado debe conducir el punto de partida de Btor (1985), pp. 157-158, para quien en el derecho sancionatorio administrativo, de conformidad con el $\S 14$, las cualidades personales requeridas por el tipo no son parte de un especial desvalor de la acción, sino sólo del desvalor del resultado, de modo que no pueden considerarse elementos o modalidades de la autoría (Tätermerkmale) sino simplemente del tipo (Tatbestandsmerkmale), cuya presencia, en cualquiera de los intervinientes (sea autor o partícipe), bastaría para considerar autor también al extraneus. En cambio, ReNGIER (2014) § 14 nm 95-98, entiende que ni aun con la norma del $\S 14$ es posible sancionar en estos casos al extraneus que se vale de un intraneus como instrumento no doloso. 
de conductor, que sólo está presente en quien no realizó la conducta descrita por la norma, sino que incurrió en un comportamiento auxiliar (materialmente, de complicidad).

La doctrina alemana, con todo, duda de que el propósito del $\S 14$ de la OWiG de simplificar la aplicación del derecho se logre con una disposición que, de todos modos exige, no sólo el recurso a las categorías de autor y partícipe, que son las que dan contenido al concepto de interviniente-ya siquiera para determinar los límites externos de esta noción-, sino también la determinación, en relación con numerosas cuestiones puntuales, de si la regla conduce a las mismas soluciones reconocidas en el derecho penal u obliga a apartarse de ellas. ${ }^{132}$ De todos modos, la posibilidad de apartarse, respecto de ciertos problemas, de las exigencias de la dogmática penal sobre la autoría y la participación, ya representa una ventaja. ${ }^{133}$

En contraste con la solución alemana, el derecho federal suizo simplemente exime de pena a los inductores y cómplices de una infracción administrativa. ${ }^{134}$ En cambio, a nivel cantonal, algunas leyes emplean un sistema numerus clausus para la extensión de la sanción a la complicidad y, en su caso, a la inducción, indicando caso a caso, junto a cada infracción, que esas formas de intervención serán sancionables. ${ }^{135}$

\subsection{Regulación alemana del actuar en lugar de otro y de la responsabilidad del superior}

En el derecho sancionatorio administrativo alemán, de igual forma como en su momento ocurrió con el derecho penal, se ha considerado necesario incorporar una cláusula expresa para sancionar, en estos casos, al que actúa en lugar de otro, cláusula recogida en el artículo 9, párrafo primero, de la OWiG, que dispone:

132 RenGier (2014), § $14 \mathrm{~nm} 3$.

133 Ibídem.

134 En efecto, en su artículo 5, la Ley Federal de Derecho Penal Administrativo -Bundesgesetz über das Verwaltungsstrafrecht- de 22 de marzo de 1974, que se aplica tanto a las infracciones administrativas -Ordnungswidrigkeiten-sancionadas sólo con multa administrativa, como a las contravenciones - Übertretungen- que pueden ser sancionadas con prisión, contempla en su artículo $5^{\circ}$ una cláusula de extensión de la sanción para la complicidad y la inducción exclusivamente aplicables para las contravenciones, no así para las infracciones administrativas (Anstiftung und Gehilfenschaft zu einer Übertretung, ausgenommen zu einer Ordnungswidrigkeit, sind strafbar).

135 Así lo hace, por ejemplo, la Ley de contravenciones penales del cantón Sankt Gallen, de 13 de diciembre de 1984; disponible en http://gesetzessammlung.sg.ch/frontend/versions/533 [visitada el 1 de abril de 2016]. En efecto, mientras la infracción de falsa alarma (art. $5^{\circ}$ ), expresamente es sancionable respecto del cómplice (y del autor de tentativa), la infracción de arrojar basura (art. $7^{\circ}$ bis) no lo es. 
"Si alguien actúa

1. como órgano con poderes de representación de una persona jurídica o como miembro de tal órgano,

2. como socio con poderes de representación de una sociedad comercial de personas, $\mathrm{o}$

3. como representante legal de otro,

entonces, cualquier ley de conformidad con la cual la posibilidad de sanción se funde en propiedades, relaciones o circunstancias personales especiales, también será aplicable al representante, cuando estas características no estén presentes en él, pero sí en el representado".

Una disposición similar contempla el derecho sancionatorio administrativo suizo, para la responsabilidad del que actúa en lugar de otro. ${ }^{136}$

Una norma de esas características zanjaría la cuestión de la sancionabilidad del representante en todos los casos en los que falta una cláusula especial y la prohibición o mandato no se extiende al "encargado" ni recurre a otra expresión que permita siquiera implícitamente entenderlo incluido.

Por lo que respecta a la responsabilidad del superior, en el derecho sancionatorio administrativo alemán, se contempla expresamente una norma sobre la responsabilidad del dueño de la empresa (§ $130 \mathrm{OWiG}$ ), conforme a la cual éste responde por su omisión dolosa o culposa ${ }^{137}$ de adoptar medidas de vigilancia necesarias para impedir infracciones contra deberes que conciernen al dueño, dentro de las cuales se incluye la obligación de una cuidadosa selección y supervisión del personal encargado de supervigilar a otros. ${ }^{138}$ Esta disposición se ve complementada con la norma sobre responsabilidad por el actuar en lugar de otro ( $\$ 9 \mathrm{OWiG})$, que permite extender la responsabilidad a los representantes legales de una persona jurídica, a los socios con poderes de administración de las sociedades de personas y a directivos de las empresas, entendiendo que todos ellos, al omitir adoptar las medidas de vigilancia están

\footnotetext{
136 Así, el Art. 6.1. de la Bundesgesetz über das Verwaltungsstrafrecht, de 22 de marzo de 1974.

137 Mención necesaria desde que se reconoce vigencia al principio de culpabilidad. En efecto, a lo menos desde la promulgación de la OWiG de 1968, que en su § 10 expresamente dispone: "[s]ólo puede sancionarse como infracción administrativa un actuar doloso, salvo cuando la ley expresamente conmina con multa administrativa un actuar imprudente". En cambio, antes de la OWiG, el derecho alemán prescindía, a lo menos en parte, de la exigencia de dolo o culpa; МıтsсH (2014), Einleitung nm 123.
}

138 Rogall (2014), § $130 \mathrm{~nm} 64$ y ss., 62 y ss. 
"actuando en lugar" del dueño, e incurriendo de esa manera en la infracción del § 130 de la OWiG. ${ }^{139}$

Fuera de ello, el § 30 de la OWiG, permite, además, aplicar directamente a la persona jurídica la multa que fue impuesta a cualquiera de los superiores mencionados, aun si no se ha podido determinar cuál de ellos no ha cumplido con el deber de vigilancia.

La responsabilidad del superior también se ha reconocido en el derecho sancionatorio administrativo suizo. ${ }^{140}$

Una regulación legal de la responsabilidad del superior, aunque no parece estrictamente necesaria para sancionar a los superiores en los casos simples, ${ }^{141}$ sí serviría para aclarar el estatuto de la responsabilidad, tanto de los dueños como de los representantes legales de la empresa, y de la propia empresa, como persona jurídica, en casos de infracciones directamente ejecutadas por empleados al interior de la misma, como ocurrió en el Caso Blackout.

\section{Conclusiones y perspectivas de lege ferenda}

La legalidad de las infracciones administrativas no exige estrictamente tipicidad de las mismas, pero sí plantea exigencias de previsibilidad de la sanción y de adecuación a la voluntad del legislador, tanto en relación con los posibles objetivos de política pública que pueden guiar su programa sancionatorio como con los propios límites que el legislador ha querido imponer a las agencias administrativas a través de una regulación más bien transitiva de su potestad sancionatoria.

En materia de autoría y participación, ello impone restricciones de distinto tipo, según cuán transitiva o intransitiva sea la definición de una determinada infracción administrativa. Si la ley, por una parte, define una conducta más o menos precisa, o identifica con claridad un cierto tipo de infractor, aludiendo a cualidades especiales que lo hacen destinatario de la norma, la posibilidad de sancionar a quienes sin haber incurrido en esa acción o sin contar con dicha cualidad, han intervenido sin embargo de una forma eficaz para que el autor incurriera en la infracción, se ve limitada por la ausencia de cláusulas de extensión de la sanción similares a las que la ley penal ha considerado para los cómplices e inductores, o para quien actúa en lugar de otro. Menos problemática puede parecer la sanción de coautores, de autores mediatos o de superiores o

139 Rogall (2014), § $130 \mathrm{~nm} 33-35$.

140 Así, el Art. 6.2. de la Bundesgesetz über das Verwaltungsstrafrecht, de 22 de marzo de 1974.

141 supra b., en el apartado 2.3. 
directivos que omiten impedir la ejecución de la infracción a sus subordinados; pero los contornos de dicha responsabilidad no están del todo claros.

Si la ley que sanciona infracciones administrativas, en cambio, es en alto grado intransitiva-como tiende a serlo una parte de la legislación moderna- la agencia administrativa encargada de implementar el programa sancionatorio puede desarrollar reglas que, persiguiendo las finalidades fijadas por el legislador para "mejorar el sector", extiendan la sanción a esos otros intervinientes, de un modo que sea previsible para ellos. Con todo, si tal decisión es adoptada de forma ad hoc por unas agencias y no otras, en ciertos sectores y no en otros, y respecto de algunas infracciones y no otras, el riesgo de estar incurriendo en una aplicación arbitraria de las sanciones establecidas por la ley no puede ignorarse.

Esas razones hablan a favor de que sea el legislador el que resuelva la sancionabilidad de las conductas de quienes no intervienen a título de autor.

Con todo, es una cuestión de política sancionatoria administrativa que requiere análisis, si acaso tiene sentido extender la punición a los diversos grupos de sujetos que vienen a cuento, más allá del autor de la infracción administrativa. Respecto de los intervinientes de primer orden es recomendable incorporar cláusulas explícitas de extensión de la sanción, a lo menos cuando determinan a otro, mediante error o coacción, a incurrir materialmente en el comportamiento prohibido, actúan en lugar o en representación del sujeto cualificado, y cuando incumplen deberes de supervisión y control sobre sus subordinados, favoreciendo que estos incurran en una infracción administrativa. También convendría aclarar de forma explícita el alcance de la responsabilidad de las personas jurídicas por los comportamientos de sus representantes y de los empleados.

Más discutible puede ser, en cambio, la necesidad de extender la sanción a los intervinientes secundarios, como quienes simplemente inducen a otro o cooperan con otro para la realización de la infracción. El interés en "mejorar el sector", en principio, podría hacer pensar que interesa una regulación catch them all. Pero la extensión desmedida a que ello podría dar lugar seguramente se traduciría pronto en una política altamente selectiva de la Administración, cuyas decisiones, nuevamente ad hoc, en la práctica podrían conspirar contra la racionalidad y previsibilidad de sus sanciones.

En todo caso, seguramente la solución no debería ser la misma para ámbitos en los cuales el interés en la mejoría del sector es muy manifiesto -hipótesis en que la legislación sectorial debería dejar espacio a la Administración para establecer reglas de extensión de la responsabilidad a estos partícipes-y aqueIlos otros ámbitos en que la persecución tiene en cierto sentido un carácter de reproche más personal $-y$, por ello, estigmatizante-, como el derecho administrativo disciplinario o el de las infracciones disciplinarias de naturaleza más contravencional. En este segundo ámbito, un criterio para decidir sancionar o 
no, a nivel legal, a los inductores y cómplices, puede ser la circunstancia de que se trate de infracciones que corresponden a delitos descriminalizados-caso en que podría tener sentido seguir permitiendo sancionar a los partícipes-o, más bien, de infracciones que nunca han tenido relevancia penal -caso en que el interés de perseguir a los partícipes podría ser reducido. ${ }^{142}$

\section{BiBLIOGRAFÍA}

AlCALDE, Enrique (2011): "Aplicación de los principios de tipicidad, culpabilidad y proporcionalidad en la infracción administrativa", en: Actualidad Jurídica ( No 24, julio 2011), pp. 63-75.

AsHwORTH, Andrew y Horder, Jeremy (2013): Principles of Criminal Law, $7^{\text {a }}$ edición (Oxford, Oxford University Press).

Bıor, René (1985): Die Beteiligungsform als Zurechnungstypus im Strafrecht (Berlin, Duncker \& Humblot).

Buck-HeEB, Petra (2010): Kapitalmarktrecht $4^{a}$ edición (Heidelberg, München, Landsberg, Frechen, Hamburg, C.F. Müller).

Chalmers, James y Leverick, Fiona (2008): "Fair Labelling in Criminal Law", en: The Modern Law Review (Volume 71, Issue 2), pp. 217-246.

Couso, Jaime (2012): "Sobre el estado actual de la noción de autor y partícipe en el Derecho chileno. En memoria del Profesor Mario Garrido Montt" (Revista Chilena de Derecho y Ciencias Penales, 2012, № 1), pp. 91-133.

Couso, Jaime (2013): "Sobre el concepto material de autor. Consideraciones dogmáticas y metodológicas en Homenaje al Profesor Enrique Cury", en: Van Weezel, Alex (Editor), Humanizar y renovar el derecho penal. Estudios en memoria de Enrique Cury (Santiago, LegalPublishing-Thompson Reuters), pp. 619-657.

Cury, Enrique (2005): Derecho Penal, Parte General 8a edición (Santiago, Ediciones Universidad Católica de Chile).

GÖHLER, Erich (1990): Gesetz über Ordnungswidrigkeiten, 9ª edición (München, Verlag Beck).

142 En base a un criterio similar evalúa GÖHLER (1990), § 14 nm 2, de forma ambivalente la introducción en Alemania de un concepto unitario de autor a través de la OWiG de 1968, que posibilitó el castigo a los cómplices, teniendo en cuenta que en ese entonces el nuevo derecho sancionatorio administrativo alemán reunió algunos antiguos delitos menores (Vergehen), para los cuales la complicidad sí era sancionable, con faltas (Übertretungen), para las cuales esa forma de intervención no era susceptible de sanción, ampliando de ese modo, respecto de estas últimas, el campo de lo sancionable más allá de lo que había parecido necesario, a lo menos durante un largo tiempo. 
Guiloff Titiun, Matías (2012): "Operativizando la relación ley-reglamento: una propuesta de redefinición del rol de la reserva legal", en: Revista de Derecho (Valdivia) (Vol. XXV - No 1 - julio 2012), pp. 127-147.

HeRnÁnDEZ, Héctor (2010): "La introducción de la responsabilidad penal de las personas jurídicas en Chile", en: Polít. Crim. (Vol. 5, No 9), pp. 207-236. Disponible en: http://www.politicacriminal.cl/Vol_05/n_09/Vol5N9A5.pdf [visitado el 11/08/2016].

Hernández, Héctor (2011): "Comentario [al Artículo 20]", en: Couso, Jaime y Hernández, Héctor (Directores), Código Penal Comentado. Parte General. Doctrina y Jurisprudencia (Santiago, Abeledo Perrot - LegalPublishing).

Hernández, Héctor (2013): "El fundamento de la posición de garante de los directivos de empresa, respecto de delitos cometidos por terceros en la misma", en: Van Weezel, Alex (Editor), Humanizar y renovar el Derecho Penal. Estudios en Memoria de Enrique Cury (Santiago, LegalPublishing-Thompson Reuters), pp. 547-582.

JACKSON, Miles (2016): "The Attribution of Responsibility and Modes of Liability in International Criminal Law", en Leiden Journal of International Law (Oxford Legal Studies Research Paper No 34/2016), pp. 13-14. Disponible en: http:// ssrn.com/abstract=2768678 [visitado el 12/08/2016].

Jakobs, Günther (1995): Derecho Penal. Parte General. Fundamentos y teoría de la imputación (Traducc. Joaquín Cuello Contreras y José Luis Serrano González de Murillo, Madrid, Marcial Pons).

KINDHÄUSER, Urs (2013): Strafgesetzbuch. Lehr- und Praxiskommentar, $5^{\text {a }}$ edición (Baden-Baden, Nomos).

LONDOÑO, Fernando (2014): "Tipicidad y legalidad en el derecho administrativosancionatorio" (Revista de Derecho (Valdivia), vol. XXVII - No 2 - diciembre 2014), pp. 147-167.

MaÑalich, Juan Pablo (2009): Nötigung und Verantwortung (Baden-Baden, Nomos).

MaÑALICH, Juan Pablo (2010): "La estructura de la autoría mediata" (Revista de Derecho (Valparaiso), núm. XXXIV, 2010), pp. 385-414.

MaÑALICH, Juan Pablo (2012): "La malversación de caudales públicos y el fraude al fisco como delitos especiales", en: Política Criminal (vol. 7, № 14, diciembre 2012), pp. 357-377.

MaÑALICH, Juan Pablo (2014a): Norma, causalidad y acción. Una teoría de las normas para la dogmática de los delitos de resultado puros (Madrid, Marcial Pons).

MaÑAlich, Juan Pablo (2014b): "Omisión del Garante e Intervención Delictiva. Una reconstrucción desde la teoría de las normas", en: Revista de Derecho Universidad Católica del Norte (año 21 - № 2, 2014), pp. 225-276. 
MIR PUIG, Santiago (1996): Derecho Penal Parte General, $4^{\text {a }}$ edición (Barcelona, PPU).

Miтsch, Wolfgang (2014): "Einleitung", en Ordnungswidrigkeitengesetz. Karlsruher Kommentar, $4^{a}$ edición (München, Verlag C.H. Beck), pp. 1-52.

MontT, Santiago (2010): "Autonomía y Responsabilidad: dos expresiones de la vocación juridificadora del derecho administrativo y sus principios fundamentales" (Documento de Trabajo para el Centro de Regulación y Competencia de la Facultad de Derecho de la Universidad de Chile).

Muñoz Conde, Francisco (2015): Derecho Penal. Parte Especial, 20ª edición (Valencia, Tirant lo Blanch).

Nersessian, David L. (2006): "Whoops, I Committed Genocide - The Anomaly of Constructive Liability for Serious International Crimes", en: The Fletcher Forum of World Affairs (Volume 30:2), pp. 81-106.

Nino, Carlos Santiago (1980): Los límites de la Responsabilidad Penal (Buenos Aires, Editorial Astrea de Alfredo y Ricardo Depalma).

Ossandón Widow, María Magdalena (2007): "El sujeto activo en los delitos tributarios", en: Revista de Derecho de la Pontificia Universidad Católica de Valparaíso (vol. V, No XXVIII), pp. 155-187.

Politoff Lifschitz, Sergio (2001): “'Cometer' y 'hacer cometer': desarrollo y significación actual de la noción de autoría mediata. El 'autor detrás del autor'. De la autoría funcional a la responsabilidad de las personas jurídicas", en: Arroyo Zapatero, Luis Alberto y Berdugo Gómez de la Torre, Ignacio (Coords.): Homenaje al Dr. Marino Barbero Santos. In memoriam (Cuenca, Ediciones Universidad de Castilla-La Mancha - Ediciones Universidad de Salamanca), volumen I, pp. 1231-1284.

ReNGIER, Rudolf (2014): "[Comentario al] § 14", en Ordnungswidrigkeitengesetz. Karlsruher Kommentar, $4^{a}$ edición (München, Verlag C.H. Beck) pp. 260-283.

Robinson, Paul (1984): "Imputed criminal liability", en: The Yale Law Journal (Vol 93, Number 4), pp. 609-676).

RogalL, Klaus (2014): “[Comentario al] § 130", en Ordnungswidrigkeitengesetz. Karlsruher Kommentar, $4^{\text {a }}$ edición (München, Verlag C.H. Beck) pp. 1746-1789.

RotsCH, Thomas (2009): Einheitstäterschaft statt Taherrschaft. Zur Abkehr von einem differezierenden Beteiligunsformensystem in einer normative-funktionalen Straftatlehre (Tübingen, Mohr Siebeck).

Roxin, Claus (1994): Strafrecht. Allgemeiner Teil. Grundlagen, Der Aufbau der Verbrechenslehre, $2^{\text {a }}$ edición (München, Verlag C.H. Beck), volumen I.

Roxın, Claus (2003): Strafrecht. Allgemeiner Teil. Besondere Erscheinungsformen der Straftat (München, Verlag C.H. Beck), volumen II. 
RoxıN, Claus (2006): Täterschaft und Tatherrschaft, $8^{a}$ edición (Berlin, De Gruyter Recht).

RuBIN, Edward L. (1989): "Law and Legislation in the Administrative State" (Columbia Law Review, Vol. 89, No 3, Apr., 1989), pp. 369-426.

SchwACKe, Peter (2006): Recht der Ordnungswidrigkeiten, $4^{\mathrm{a}}$ edición (Stuttgart, Deutsche Gemeindeverlag/Verlag W. Kohlhammer).

Silva SÁnchez, Jesús-María (1992): Aproximación al Derecho Penal Contemporáneo (Barcelona, José María Bosch, Editor)

Soto Delgado, Pablo (2015): "Un mal caso para flexibilizar la tipicidad en el derecho administrativo sancionador. Comentario al fallo "Empresa de Servicios Sanitarios Essbio S.A. con Seremi de Salud del Biobío" de la Corte Suprema, rol No 7397-2012", en: Revista Chilena de Derecho (vol. 42 № 2), pp. 701-714.

VAN WeEZEL, Alex (2011): La garantía de tipicidad en la jurisprudencia del Tribunal Constitucional (Santiago, Abeledo Perrot-Thomson Reuters).

Van Weezel, Alex (2013): "Actuar en lugar de otro", en: La ciencia penal en la Universidad de Chile. Libro Homenaje a los Profesores del Departamento de Ciencias Penales de la Facultad de Derecho de la Universidad de Chile (Santiago, Facultad de Derecho, Universidad de Chile).

Von WriGht, Georg Kenrik (1963): Norm and Action. A Logical Enquiry (London

- Henley, Routledge \& Kegan Paul).

Williams, Glanville (1983): "Convictions and fair labelling", en: The Cambridge Law Journal (Vol. 42, № 1 (Apr., 1983)) pp. 85-95.

ZúNíiga URBINA, Francisco (2015): "El retorno a lo administrativo: Comentario a la sentencia rol No 1079-2014 de la Corte Suprema, 'Fisco de Chile con Dörr Zegers y otros' ('Chispas II')', en Estudios Constitucionales, año 13, No 1, 2015, pp. 399-416. 